\title{
Spatio-temporal rainfall trend and homogeneity analysis in flood prone area: case study of Odaw river basin-Ghana
}

\author{
Edward Kofi Ackom ${ }^{1,2}$ D $\cdot$ Kwaku Amaning Adjei $^{1} \cdot$ Samuel Nii Odai ${ }^{1,3}$
}

Received: 26 May 2020 / Accepted: 19 November 2020 / Published online: 3 December 2020

(c) Springer Nature Switzerland AG 2020

\begin{abstract}
Accurately forecasting rainfall trends is vital for the socio-economic development of a nation. Observed daily rainfall data from the Ghana Meteorological Agency (GMet) spanning 1980 - 2015 was deployed to study the spatio-temporal rainfall trend in the Odaw river basin (ORB) in Accra. Using Mann-Kendall (MK), Sen's slope and set of homogeneity tests, the monthly, annual and decadal rainfall variability based on the indices - rainfall total, daily maximum and rainy/wet day count were examined. Principal Component Analysis (PCA) and wavelet (WT) analysis were applied on the monthly time series in order to verify the spatio-temporal variability. It was observed that a mean value ranging from 760 to $1200 \mathrm{~mm}$, 77.1-94.4 mm and 56-90 day count were recorded for Annual Rainfall Total (ART), Annual Daily Maximum (ADM) and Annual Rainy Days (ARD) respectively in the ORB. Mann-Kendal test recorded an overall non-significant positive trend in the Odaw basin for ART and ARD with an average positive slope of $3.7 \mathrm{~mm} /$ year and 0.23 wet days/year and a significant positive trend with slope value of $0.55 \mathrm{~mm} /$ year for ADM in the basin. On the monthly scale, a significant upward trend was observed for the dry seasonal months; December, January and February for the Monthly Rainfall Total (MRT) and Monthly Daily Maximum (MDM) rainfall series during the period at all stations. Homogeneity for both annual and monthly rainfall time series were observed over the stations in the basin by the Pettitt, Alexandersson's SNHT and Buishand's tests. PCA revealed that the spatial variability of rainfall in ORB is very diverse with $55.9 \%$ of the variability located in the middle to highland part while $44.0 \%$ of the variation is occurring mostly in the low-lying area at the southeastern part of the ORB. The wavelet analysis also revealed a strong annual periodicity at all the selected stations in the basin. The outcome of this study provides valuable information to formulate adaptation measures through appropriate strategies for managing flood in the study area.
\end{abstract}

Keywords Trend · Homogeneity · Mann-Kendal Test · Sen's Slope Estimator · PCA, Wavelet Analysis · Odaw river basin

\section{Introduction}

Rainfall is described as one of the main climate variables which drives the spatio-temporal trends of water availability. It is known internationally that over the last ten decades, climate has changed a great deal. One of the main problems confronting the climate change/variability scientists is to ascertain, recognize and quantify the trends in rainfall and their consequences on hydrology so as to aid in planning adaptation strategies for water resources management and sustainable development $[3,8]$. Variations in rainfall patterns plays a significant role in the hydrological process and may result in flood or drought in various locations which has a direct effect on socio-economic activities such as agriculture, water supply, hydropower generation, health among others, of any nation $[4,10$,

Edward Kofi Ackom, ackomek@gmail.com | ${ }^{1}$ Regional Water and Environmental Sanitation Center, Kumasi (RWESCK), Department of Civil Engineering, College of Engineering, KNUST, Kumasi, Ghana. ${ }^{2}$ Community Water and Sanitation Agency, Accra, Ghana. ${ }^{3}$ Accra Technical University, Accra, Ghana. 
$14,18,29,36,45]$. Studies have shown that, due to growing variability in rainfall patterns, people's ability to plan for future flooding has become more difficult [5]. Lack of understanding of the spatio-temporal dynamics of rainfall has implications for the management of water resources, particularly in flood and drought situations of a region. The understanding of spatio-temporal rainfall trend of an area will serve as a useful informative tool in the effective water management.

The extensive studies on the spatio-temporal rainfall trend which has been carried out in places such as USA, UK, South Africa and the Caribbean indicate the detection of positive trend in annual precipitation, whereas negative trend of annual precipitation has been shown in some part of western Africa [46]. In Ghana, some works on analysis of rainfall trends using observed data has been conducted in different regions [22, 27, 34], and the results demonstrate a general decreasing trend in annual rainfall. Logah et al. [27] found a general decline in mean annual rainfall for the period 1981-2010 with high rainfalls shifting to the South-western corner of the country. Accra showed slight increase in the mean annual rainfall for the past three decades. Nyatuame et al. [34] observed no significant detectable effect of climate change on both the of annual rainfall and monthly trend in Volta Region of Ghana during 1981-2011 while Lacombe et al. [26] observed no significant changes in annual rainfall for the period 1960-2005.

Regional changes in rainfall can be much bigger, and substantial spatio- temporal rainfall trends may occur at different locations as a result of spatial variations in the rainfall and temperature and the variations in the catchment characteristics $[12,48]$. Changes in land use and land cover can influence the spatial and temporal variations in precipitation and temperature [1, 22]. Spatio-temporal characterization of precipitation can also be analyzed by monitoring the network of rain gauges in the study area. Rain gauges are the most common instruments used to quantify the variability of precipitation. In tropical regions, rain gauge data scarcity, climate instability, and variable spatial accessibility render traditional methods insufficient and impractical for designing rain gauge networks [31,44]. The modern method, such as conditioned Latin hypercube sampling (CLHS), has led to the capture of spatio-temporal precipitation patterns in ungauged areas through multitemporal layers of remotely sensed precipitation measurements [13].

Various statistical test approaches are applied to identify trends in hydro-meteorological datasets grouped as parametric and nonparametric tests. Parametric tests are more effectual but the data need to be independent and normally distributed, which is not often factual for hydrological dataset. With the nonparametric tests, independently nature of the data is required, but outliers are better accepted. The widely used nonparametric tests on time series data, Mann-Kendall [25, 30] and Principal Component Analysis (PCA), wavelet analysis (WT) was adopted for the study. Principal Component Analysis (PCA) and wavelet analysis has been applied $[11,39]$ to study respectively the spatiotemporal dynamics of rainfall in Upper East Region of Ghana during the period 1981-2016 and the whole of Ghana, while Othman et al. [38] applied PCA on Long-term daily rainfall pattern recognition in Malaysia.

Homogeneity test on rainfall datasets have been studied by a lot of researchers globally $[15,17,23,24,28,37,42$, $43,47]$. Several factors such as station relocation, changes in instruments, formulae used to calculate mean and many other factors can affect the quality, accuracy and reliability of climate data. The proper statistical testing of data quality, consistency, and homogeneity is therefore crucial when conducting any climate analysis and hydrological research [41]. The Pettitt test, Buishand's test and Alexandersson's SNHT test were used in this study to test homogeneity in the rainfall time series.

The Odaw river basin located at the middle part of the city of Accra and draining about $60 \%$ of the city has been challenged with urban storm water management for the past three decades resulting in what can be described as perennial floods. A typical flood disaster occurring in recent years with huge impact was the June 3, 2015 flood event which hit Accra leading to the explosion of a fuel station claiming 152 lives and destroyed lots of properties while displacing hundreds of people [5]. Various factors have been identified by key stakeholders and through research work as the causes of flooding in Accra including increasing intensity of rainfall events, poor management of surface water resources, uncontrolled urbanisation, residential development in flood-prone areas, and perceived or real impacts of climate variability and change [6]. Concerns about whether the city of Accra is experiencing more rainfall, shifts in frequency or rises in rainfall intensity have been raised. However, there is no comprehensive research on rainfall amounts, rainfall intensity and rainy (wet) days changes in the ORB. Understanding the changing pattern of rainfall intensity, duration and frequency (IDF) is of great concern and a requirement for the development of rainfall Intensity - Duration -Frequency (IDF) curves used for design of urban water management infrastructure to address flooding.

The key objective of this study therefore, is to investigate the spatial and temporal trend and variability of monthly, annual and decadal rainfall time series. It involves the analysis of rainfall variables including rainfall total, rainy (wet) days count, and daily maximum rainfall over a period 1980-2015 in the Odaw river basin of Accra. The outcome of this study will help provide valuable database 
for formulating adaptation measures through appropriate strategies for managing flood in the study area.

\section{Study area and data used}

\subsection{Study area}

The Odaw river basin is one of the nine sub-basins in Accra bounded by three Metropolitan/Municipal Assemblies; Accra Metropolitan, Ga (East and West) and Tema Municipal (Fig. 1). It lies within longitudes $0^{\circ} 1^{\prime} \mathrm{W}$ and $0^{\circ} 15^{\prime} \mathrm{E}$ and latitudes $5^{\circ} 30^{\prime} \mathrm{N}$ and $5^{\circ} 50^{\prime} \mathrm{N}$ in the dry equatorial climatic zone. The total catchment area of the Odaw basin is $272.176 \mathrm{~km}^{2}$ and has a length of about $5.41 \mathrm{~km}$. The river takes its source from the headwater at Akuapem hills near Aburi and meanders its way to the southern direction and finally discharges into the sea (Atlantic Ocean) through the Korle Lagoon which is main repository of most streams in Accra (Fig. 1).

The area falls within the Equatorial climate zone of Ghana, which is affected by two major winds; the Atlantic Ocean's moisture-laden Southwest Monsoon winds, responsible for precipitation events, and the Saharan desert's North-east Trade Winds (Harmattan), responsible for dry and hazy dry times. It falls within Accra's geomorphic western coastal portion [35]. The area experiences a bimodal rainfall pattern annually described as major and minor rainy season. The major rainy season begins from April to June and the minor rainy season occurs from September to October. The total annual precipitation over the two season averages $730 \mathrm{~mm}$. Rainfall duration is usually short but intense and this leads to flooding especially in areas where drainage channels are blocked ([7]). The warmest month in the year is March with an average temperature of $28^{\circ} \mathrm{C}$. At $24.7^{\circ} \mathrm{C}$ on the average, August is considered the coldest month of the year [16]. Relative humidity ranges from $65 \%$ in the mid-afternoon to $95 \%$ at night [19]. Flooding has been a major Water Resources Management challenge in the basin both past and present.

The topography is characterized by lowlands and occasional hills. The average elevation is $20 \mathrm{~m}$ above sea level with elevation ranges from $7 \mathrm{~m}$ to $462 \mathrm{~m}$ above mean sea level (Fig. 1). The slopes are generally gentle, mostly below $11 \%$, except few places such as McCarthy hills and Kwabenya hills, where slopes are above $22 \%$ [33].

\subsection{Data used}

The time series of daily observed rainfall over a period of 36 years (1980-2015) were obtained from the Ghana Meteorological Agency. Three active rain gauge stations, devoid of data gaps; Airport, Pokuase, and Aburi were selected for the study out of the eight rain gauge stations identified in the Odaw basin. While considering more stations would be fair, there are constraints due to data gaps and unequal time series lengths. Thus the analysis considers a skeleton number of stations. The locations of rainfall gauge stations are shown in Fig. 1. Aburi is situated in the north part of the basin (highlands, more close to the headwaters of the basin - altitude of the station: $457.2 \mathrm{~m}$ ), Pokuase in the middle east part of the basin (more close to moderate altitudes of the basin - altitude of the station: $50.3 \mathrm{~m}$ ) and Airport is in the southwest part of the basin (more close to the lowlands of the basin - altitude of the station: $67.7 \mathrm{~m}$ ) (Table 1).

\section{Methodology}

The methodology used to investigate the spatio-temporal variability of rainfall and its impact in the Odaw river basin is summarized in Fig. 2. Monthly, annual and decadal time series based on the three rainfall indices - rainfall total, daily maximum rainfall and rainy (wet) days were used for the analysis. The rainy day counts is defined by GMet as number of days with precipitation depth greater or equal to $0.85 \mathrm{~mm}$.

The statistical properties such as minimum, maximum, mean, standard deviation and coefficient of variability were estimated from the annual and monthly rainfall data for the period 1980-2015 and analyzed for each station. The Mann-Kendall (MK) tests was used to detect the presence of annual and monthly rainfall trend whilst the Theil and Sen's slope test was used to estimate the magnitude of the annual and monthly trend.. The annual and monthly rainfall series was also submitted to a homogeneity and break point analysis test to check for the significance of probable break point using the Pettitt, Alexandersson's SNHT and Buishand's tests. Wavelet analysis and PCA were performed on the data to detect the rainfall frequencies/ periodicity and to capture the spatial and temporal trend in annual and monthly rainfall respectively in the Odaw river basin. Each statistical test was carried out at $5 \%$ level of significance.

\subsection{Trend detection analysis}

\subsubsection{Mann-Kendall test (MK)}

The Mann-Kendall test is a non-parametric test frequently used for the detection of significant trends in hydrological data series $[25,30]$. The MK test statistics $S$ for a series $X_{1}$, $\mathrm{X}_{2}, \ldots \mathrm{Xn}$ is defined as: 
Fig. 1 Location of the Odaw River Basin and gauge stations with DEM in Accra

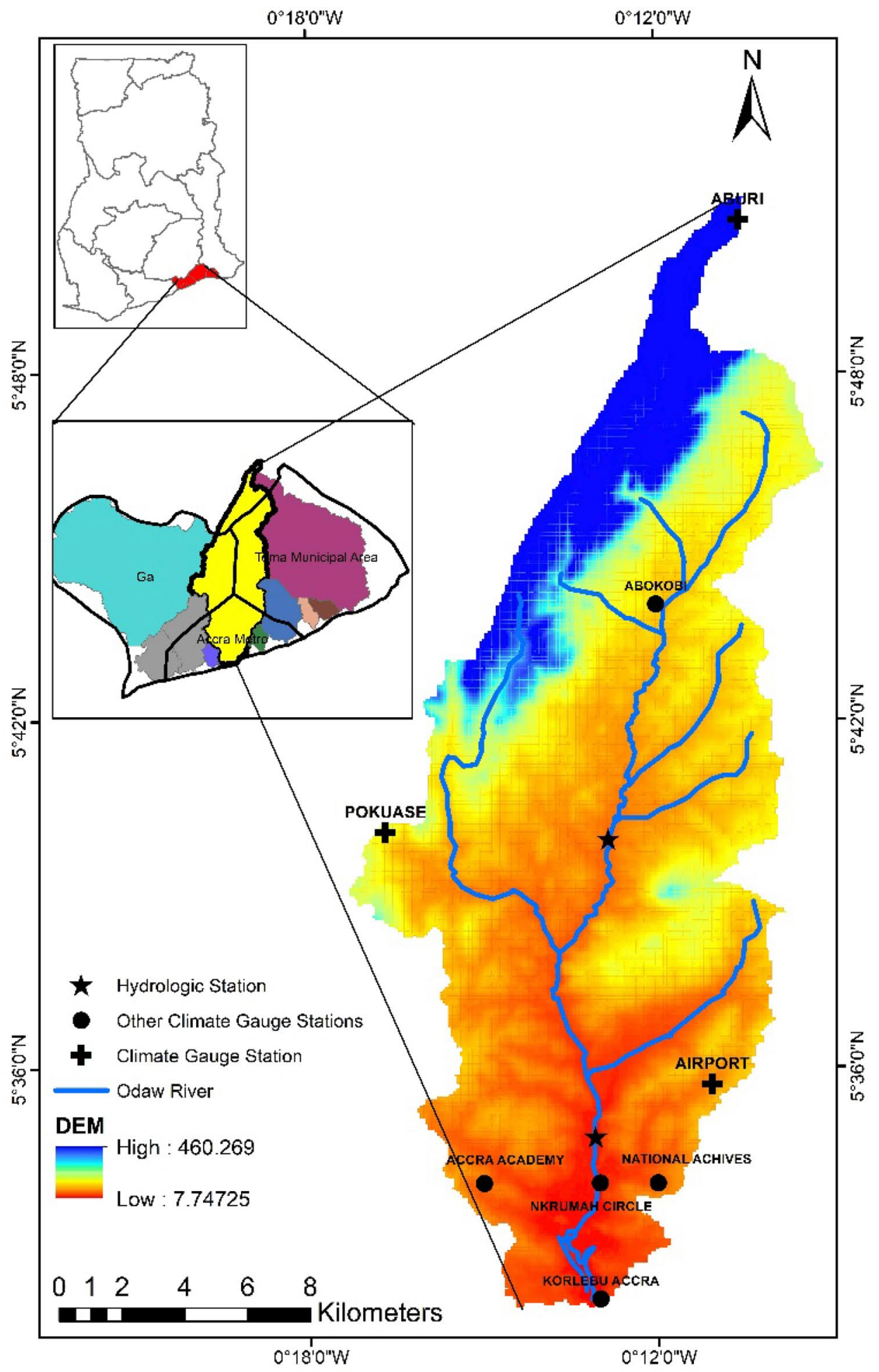

(1) where $X_{i}$ is ranked from $I=1,2, \ldots n-1, X j$ is ranked from $j=I+1$, and $n$ is the length of the data set 
Table 1 List of Abbreviation

\begin{tabular}{ll}
\hline ADM & Annual Daily Maximum \\
ARD & Annual Rainy Days \\
ART & Annual Rainfall Total \\
AMA & Accra Metropolitan Assembly \\
GMet & Ghana Meteorological Agency \\
HSD & Hydrological Service Department \\
IDF & Intensity - Duration - Frequency \\
IDM & Inverse Distance Method \\
IDW & Inverse Distance Weighting \\
MDM & Monthly Daily Maximum \\
MRD & Monthly Rainy Days \\
MRT & Monthly Rainfall Total \\
MWRWH & Ministry of Water Resources, Works and Housing \\
NADMO & National Disaster Management Organization \\
ORB & Odaw River Basin \\
\hline
\end{tabular}

$\operatorname{Sgn}\left(X_{j}-X_{i}\right)=\left\{\begin{array}{cc}1 \ldots \ldots \text { if } & X_{j}-X_{i}>0 \\ 0 \ldots \ldots \text { if } & X_{j}-X_{i}=0 \\ -1 \ldots \ldots \text { if } & X_{j}-X_{i}<0\end{array}\right.$

Positive (negative) signs of the test statistics $S$ indicate upward (downward) trend in the data. For the sample size $\mathrm{n}>=8$, variance of the Mann-Kendall statistics is given by:

$\operatorname{Var}(S)=\frac{\left[n(n-1)(2 n+5)-\sum_{i=1}^{g} e_{i}\left(e_{i}-1\right)\left(2 e_{i}+5\right)\right]}{18}$

where $e_{i}$ is the number of ties present up to sample $i$.

The standardized MK test statistics $\left(Z_{m k}\right)$ can be estimated with the equation:

$Z_{m k}=\left\{\begin{array}{ccc}\frac{s-1}{\sqrt{\operatorname{Var}(S)}} \ldots \ldots \ldots \ldots & \text { if } & S>0 \\ 0 \ldots \ldots & \text { if } & S=0 \\ \frac{S+1}{\sqrt{\operatorname{Var}(S)}} \ldots \ldots \ldots \ldots & \text { if } & S<0\end{array}\right\}$
Fig. 2 Flowchart for Spatiotemporal rainfall trend, PCA and Wavelet analysis in ORB

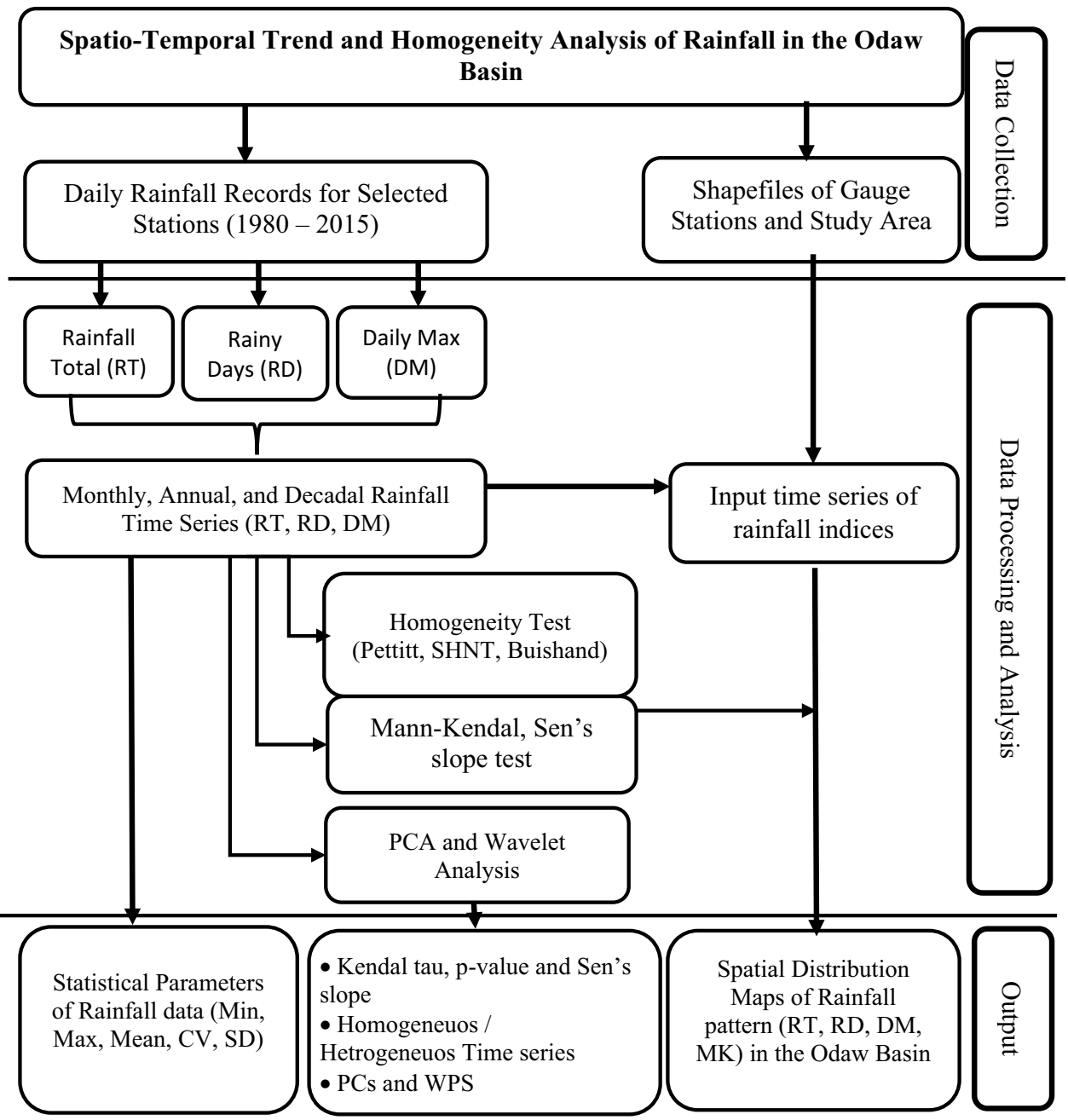


$Z_{m k}$ follows a standard normal distribution; thus, a positive value implies an upward trend while a negative value means a downward trend. If the value of $Z_{m k}$ is greater than $Z_{a / 2}$, where alpha is significant level, then it is considered a significant trend and the null hypothesis is rejected.

\subsubsection{Theil Sen's slope}

This is a nonparametric method that assumes a linear trend in the time series data and an uncorrelated data. This method is robust to missing data and outliers in the data series. It quantifies the median (50th percentile) concentration changes linearly with time and is used to determine the magnitude of the trend line. The slope of the trend line in the sample of $\mathrm{N}$ pairs of data can be estimated by:

$Q=\frac{X_{j}-X_{i}}{j-i}$

where $X_{j}$ and $X_{i}$ are the data values at times $j$ and $i(j>i)$ respectively.

The median of these $\mathrm{N}$ values of $\mathrm{Q}$ is Sen's estimator of slope which is calculated as

$\beta=Q\left(\frac{N+1}{2}\right)$ if $N$ is odd

$\beta=\left(Q\left(\frac{N}{2}\right)+\frac{Q(N+2)}{2}\right)$ if $N$ is even

A positive value of $\beta$ indicates an increasing trend and a negative value indicates a decreasing trend in the time series.

The $\beta$ sign reflects data trend direction, while its value indicates the steepness of the trend. Obtaining the confidence interval of $\beta$ at specific probability helps to determine whether the median slope is statistically different than zero. The confidence interval about the median slope can be computed as follows:

$C_{\alpha}=Z_{1-\alpha / 2} \sqrt{\operatorname{Var}(S)}$

where $\operatorname{Var}(S)$ is

$\operatorname{Var}(S)=\frac{\left[n(n-1)(2 n+5)-\sum_{i=1}^{g} e_{i}\left(e_{i}-1\right)\left(2 e_{i}+5\right)\right]}{18}$

$Z_{1-\alpha / 2}$ is obtained from the standard normal distribution table. The lower and upper limits of confidence interval, M1 and $\mathrm{M} 2$ are computed as;

$M_{1}=\left(\frac{N-C_{\alpha}}{2}\right)$
$M_{2}=\left(\frac{N+C_{\alpha}}{2}\right)$

Theil-Sen estimator is used to calculate the trend slopes.

\subsection{Homogeneity test and break point analysis}

Three absolute homogeneity tests were applied to detect discontinuities caused by non-climatic causes: Pettit's test (Pettitt, 1979), Standard Normal Homogeneity Test (SNHT) (Alexandersson, 1986), and Buishand's (Buishand, 1982).

\subsubsection{Pettitt test}

This test is a non-parametric test which does not require any assumption of normality. The test is based on the ranking order of the Yi values. The statistic is given as follows:

$X_{d}=2 \sum_{i=1}^{d} r_{i}-d(n+1) \quad d=1,2,3,4 \ldots \ldots \ldots \ldots n$

The break is detected near the year $m$ given that

$\left.X_{m}=\max _{1 \leq d \leq n}\left|X_{d}\right|\right)$

If $X_{m}$ is less than the critical value, the number series is considered uniform.

\subsubsection{Alexandersson's SNHT test}

Alexanderson (1986) describes a statistic $T(k)$ to compare the mean of the first $k$ years of the time series record with that of the last $n-k$ years:

$T(k)=k \bar{z}_{1}^{2}+(n-k) \bar{z}_{2}^{2} \quad k=1, \ldots \ldots \ldots n$

where

$\bar{z}_{1}=\frac{1}{k} \sum_{i=1}^{k}\left(Y_{i}-\bar{Y}\right) / s \quad$ and $\bar{z}_{2}=\frac{1}{n-k} \sum_{i=k+1}^{n}\left(Y_{i}-\bar{Y}\right) / s$

If a break is located at the year $K$, then $T(k)$ reaches a maximum near the year $k=K$. The test statistics $T_{0}$ is defined as:

$T_{0}=\max _{i \leq k<n} T(k)$

The null hypothesis will be rejected if $\mathrm{T}_{0}$ is above a certain level, which is dependent on the sample size. 


\subsubsection{Cumulative deviation (Buishand's test)}

Tests for homogeneity are based on the adjusted partial sums or cumulative deviations from the mean, which are expressed as:

$S_{k}^{*}=\sum_{i=1}^{k}\left(x_{t}-\bar{x}\right), k=1,2, \ldots, n$

Rescaled adjusted partial sums $\left(S_{k}^{* *}\right)$ are obtained by dividing $S_{k}{ }^{*}$ by the sample standard deviation $\left(D_{x}\right)$.

$S_{k}^{* *}=\frac{S_{k}^{*}}{D_{x}}, k=1,2, \ldots, n$

$D_{x}^{2}=\frac{1}{n} \sum_{t=1}^{n}\left(x_{t}-\bar{x}\right)^{2}$

Homogeneity tests are based on the rescaled adjusted partial sums. Sensitivity to the departures from homogeneity is defined by the following statistic:

$Q=\max _{0 \leq k \leq n}\left|S_{k}^{* *}\right|$

$R=\max _{0 \leq k \leq n}\left|S_{k}^{* *}\right|-\min _{0 \leq k \leq n}\left|S_{K}^{* *}\right|$

High values of $Q$ and $R$ are indication for non-homogeneity in the time series. If $\mathrm{Q} / \mathrm{Sqrt}(\mathrm{n})$ is greater than the critical value, the number series is not uniform.

The criteria by Wijngaard et al. [47] and Ahmad and Deni [2] were adopted for the overall homogeneity classification depending on the number of tests rejecting the null hypothesis. The following classification are distinguished:

'Very Useful Homogeneous Time Series' - three tests reject the null hypothesis at $5 \%$ level.

'Useful Homogeneous Time Series' - one test reject the null hypothesis at $5 \%$ level.

'Doubtful Non-homogenous Time series' - two tests reject the null hypothesis at 5\% level 'Suspected Nonhomogenous Time Series' - three tests fail to reject the null hypothesis at $5 \%$ level.

\subsection{Principal component analysis (CA)}

Principal Component Analysis (PCA) is a multivariate statistical analysis that seeks to simplify a complex collection of interrelationships by creating one or more new variables in relation to those that enable the overall spatial relationship to be analyzed more conveniently. By isolating a number of components with respect to newly identified axes, each of which corresponds to a variable, PCA tries to explain the total variance in a data set [20, 21]. The eigenvectors referred to as empirical orthogonal functions (EOF) describe the spatial variability for a spatiotemporal variability analysis, while the eigenvalues or main component (PC) describe the variances in the time variability [39]. PCA is a useful method that was applied to precipitation time series of 3 weather stations in the Odaw river basin. Monthly PCA analysis is carried out for the period (1980-2015) of the stations of Odaw river basin.

\subsection{Wavelet analysis}

Wavelets analysis is a standard method for analyzing localized power variations within a time series. One can establish the dominant modes of variability and how those modes differ in time by decomposing a time series into time-frequency space. Wavelet transform (WT) has been used to investigate signals in various research fields and has demonstrated dominance in the study of time series frequency and time localization [11, 39]. Using wavelet analysis, various time series characteristics such as duration, intensity and trend consistency can be defined, while the variance plot can be used to analyze multi-scale trends [39]. When a mother wavelet is selected to break down the initial time series, WT yields better results. Wavelet analysis is a suitable method applied to study the monthly rainfall variation of 3 weather stations in the Odaw river basin during the period (1980-2015). Further details on wavelet analysis implementation can be found in several research work $[11,32,40]$.

Table 2 List of rain gauge stations in the study area

\begin{tabular}{llllllll}
\hline Station Name & Station No. & Station ID & Date Opened & Latitude & Longitude & Altitude (m) & Region \\
\hline Pokuase & $0500-014-23$ & 22014 POK & $01 / 07 / 1942$ & $05^{\circ} 41^{\prime} \mathrm{N}$ & $00^{\circ} 17^{\prime}$ W & 50.3 & GT. ACCRA \\
Accra - Airport & $0500-016-23$ & $23016 \mathrm{ACC}$ & $01 / 01 / 1952$ & $05^{\circ} 36^{\prime} \mathrm{N}$ & $00^{\circ} 10^{\prime}$ W & 67.7 & GT. ACCRA \\
Aburi (Gardens) & $0500-029-23$ & $23029 \mathrm{ABU}$ & $01 / 05 / 1891$ & $05^{\circ} 51^{\prime} \mathrm{N}$ & $00^{\circ} 59^{\prime} \mathrm{W}$ & 457.2 & EASTERN \\
\hline
\end{tabular}




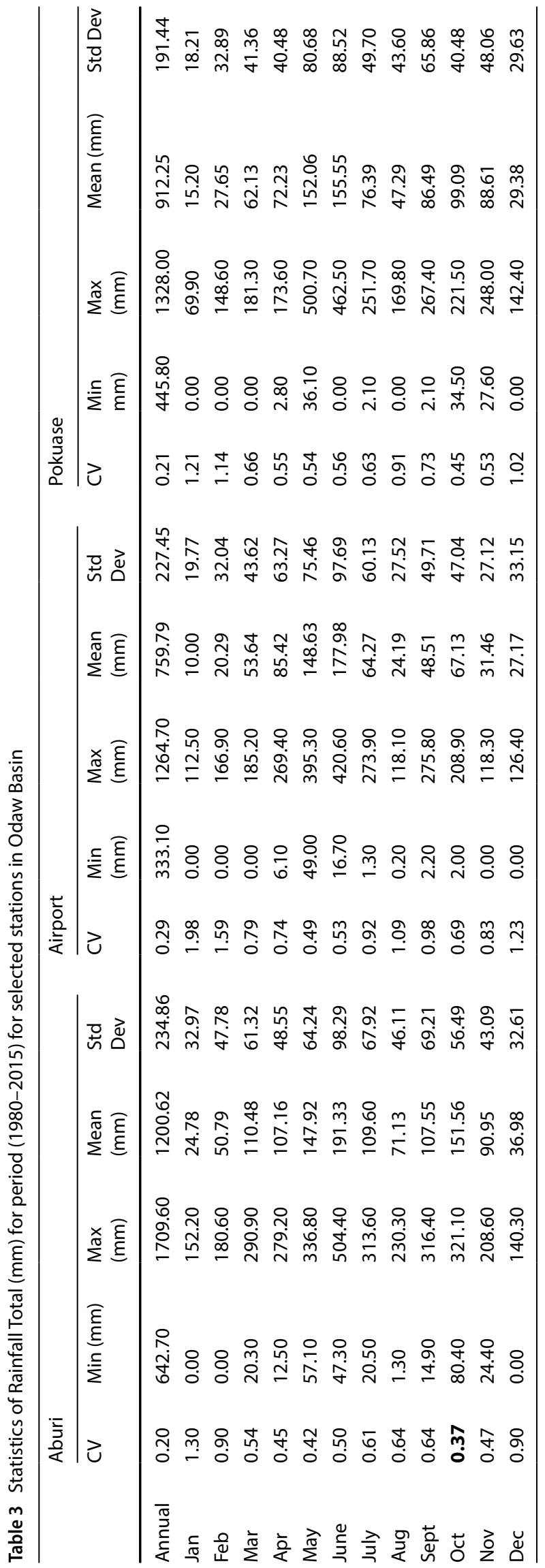

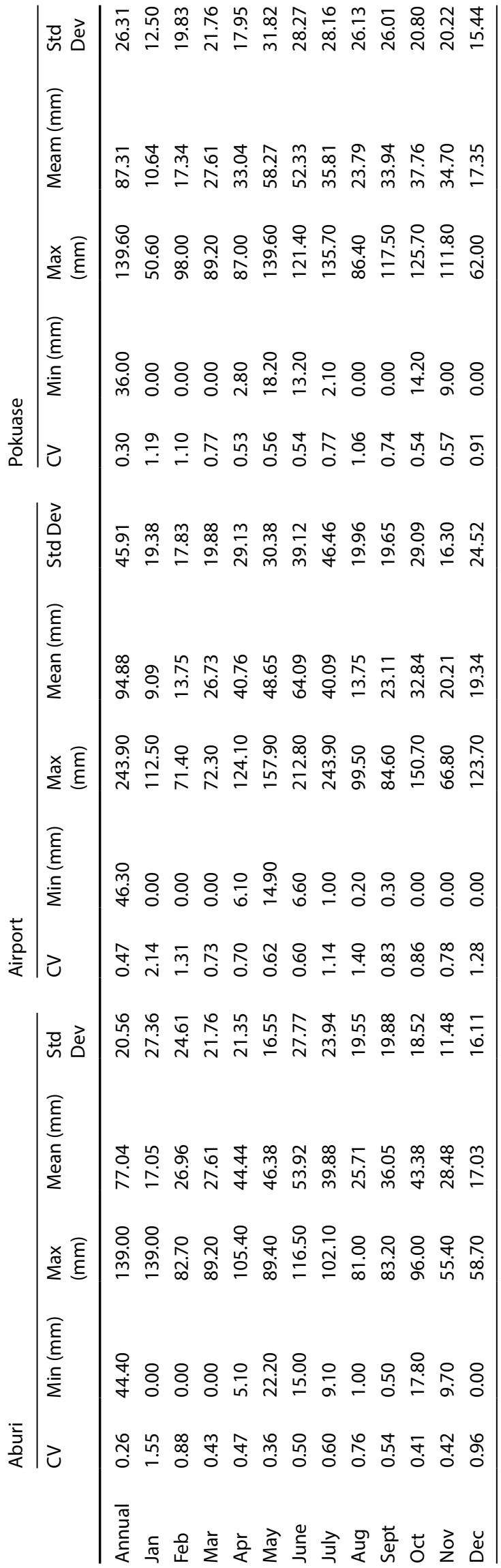




\section{Results and discussion}

\subsection{Preliminary analysis of rainfall time series}

The result of the descriptive statistics analysis of annual and monthly rainfall for the three indices - rainfall total, daily maximum and rainy (wet) days during the period 1980-2015 is shown in Tables 2, 3 and 4 respectively. At the annual scale, the recorded minimum and maximum ART during the 36 years for Aburi, Airport and Pokuase are $642.7 \mathrm{~mm}$ and $1709.6 \mathrm{~mm}, 333.1 \mathrm{~mm}$ and $1264.7 \mathrm{~mm}$, and $445.8-1328.0 \mathrm{~mm}$ respectively. All the minimum values of ART at the respective stations occurred in 1983 while the maximum values occurring in 1999, 2008 and 2010 respectively. In the case of ADM, the minimum and maximum values recorded at Aburi, Airport and Pokuase during the period were: $44.4 \mathrm{~mm}$ and $139 \mathrm{~mm}, 46.3 \mathrm{~mm}$ and $243.9 \mathrm{~mm}$ and $36 \mathrm{~mm}$ and $139.6 \mathrm{~mm}$ respectively. The corresponding years these were recorded are 2001 and 2010 for Aburi, 1983 and 1995 for Airport and 1983 and 2008 for Pokuase. The recorded minimum and maximum values for ARD are: 59 and 116, 30 and 73,35 and 87 for Aburi, Airport and Pokuase respectively with the corresponding years of occurrence being 1983 and 1999, 1998 and 2008, 1983 and 2011. The coefficient of variation (CV) varied from 19.5\% (Aburi) - 29.0\% (Airport), 13.1\% (Aburi) - 18\% (Pokuase) and 25.9\% (Aburi) $-46.9 \%$ (Airport) for ART, ARD and ADM respectively.

It is worth noting that the years $(1995,1999,2008$, 2010 and 2011) in which the maximum recorded values of the rainfall indices were recorded were actually the years the basin recorded flooding which agrees with the study by Amoako and Boamah [6].

The spatial distribution of mean annual rainfall for ART, ADM and ARD from 1980 to 2015 is shown in Fig. 4. Throughout the 36 years, the most maximum ART occurred at the northern (highland) part of ORB around Aburi station with a mean annual rainfall of 1120-1200 mm. The lowest ART occurred in the southeastern (lowland) part of the ORB around the Airport station with a mean annual rainfall of $760-817 \mathrm{~mm}$. The basin recorded a mean ART ranging between 760 and $1200 \mathrm{~mm}$ during the period 1980-2015. The highest ADM recorded in the ORB occurred at the southeastern (lowland) part with a mean ADM rainfall of 92-94.8 mm. The lowest ADM occurred in the northern (highland) part of the ORB with a mean ADM rainfall of 77.1-81.4 mm. A mean ADM ranging between 77.1-94.8 mm was recorded in the basin during the period 1980-2015. Similar to the ART spatial trend, the ARD recorded its highest value within the period at the northern (highland) area of the ORB with a mean wet days count ranging between
83 and 90 count/year. The lowest ARD occurred in the southeastern part with a mean ARD of 55-60 count/year. A mean ARD ranging between 56 and 90 count/year was recorded in the basin during the period 1980-2015.

The spatio-temporal variation of monthly rainfall time series for MRT, MDM and MRD is shown in Fig. $3 a, b$, c. The maximum value of MRT recorded in the basin at Aburi, Airport and Pokuase were $504 \mathrm{~mm}, 420.6 \mathrm{~mm}$ and $500.7 \mathrm{~mm}$ respectively with the corresponding month and year of occurrence being June 1999, June 2002 and May 1991. Similarly, maximum MDM values recorded in the basin at Aburi, Airport and Pokuase were $139 \mathrm{~mm}, 243.9 \mathrm{~mm}$ and $139.9 \mathrm{~mm}$ respectively occurring on January 2010 , July 1995 and May 2008.

The temporal rainfall pattern for all the three climatic variables; MRT, MDM and MRD can be described as bimodal rainy patterns [35] for all the selected stations. The peak of the major season occurring in June and the peak of the minor season occurs in October.

The spatial trend of the coefficient of variation (CV) indicates that low CV occurs at the northern (highland) part of the basin recording high amount of rainfall and high CV occurs at the southern (lowland) part of the basin with a low recorded rainfall amount (Fig. 3 a, b, c). In the case of temporal trend, high CV is recorded in the dry seasonal months (December, January, February, March and August). Low CV however, is recorded in the rainy(wet) seasonal months. These findings of variations in rainfall are similar to studies by Ofori-Sarpong and Annor [35] on the the rainfall over Accra during the period 1901-1990 especially in the 1961-1990 subset of the analysis.

\subsection{Homogeneity test of annual and monthly time series}

The annual and monthly time series of rainfall total, daily maximum rainfall and rainy (wet) days were considered for the homogeneity test using the Pettitt's test, SHNT test and Buishand (cumulative deviation). This was necessary to ascertain the quality and reliability of the data and the corresponding gauge station which will then be the basis for the selection of rainfall time series required for the hydrological modelling as part of this research work (Fig. 4).

On the annual scale, a $p$ value $<0.05$ was recorded under Pettit test for ART at Aburi and SHNT test for ARD at Pokuase stations (Tables 9 and 11). The rest of the time series recorded $p$ value $>0.05$ for all the selected gauge stations in the Odaw basin. This results gives an overall classification of very useful homogenous time series for ART, ARD and ADM at Airport station and useful homogenous time series for ART, ARD and ADM at Aburi and Pokuase stations. This implies that in terms of space and time, the 
Fig. 3 Monthly variation of rainfall indices in the Odaw basin (a) Rainfall Total, (b) Rainy Days count (c) Daily maximum
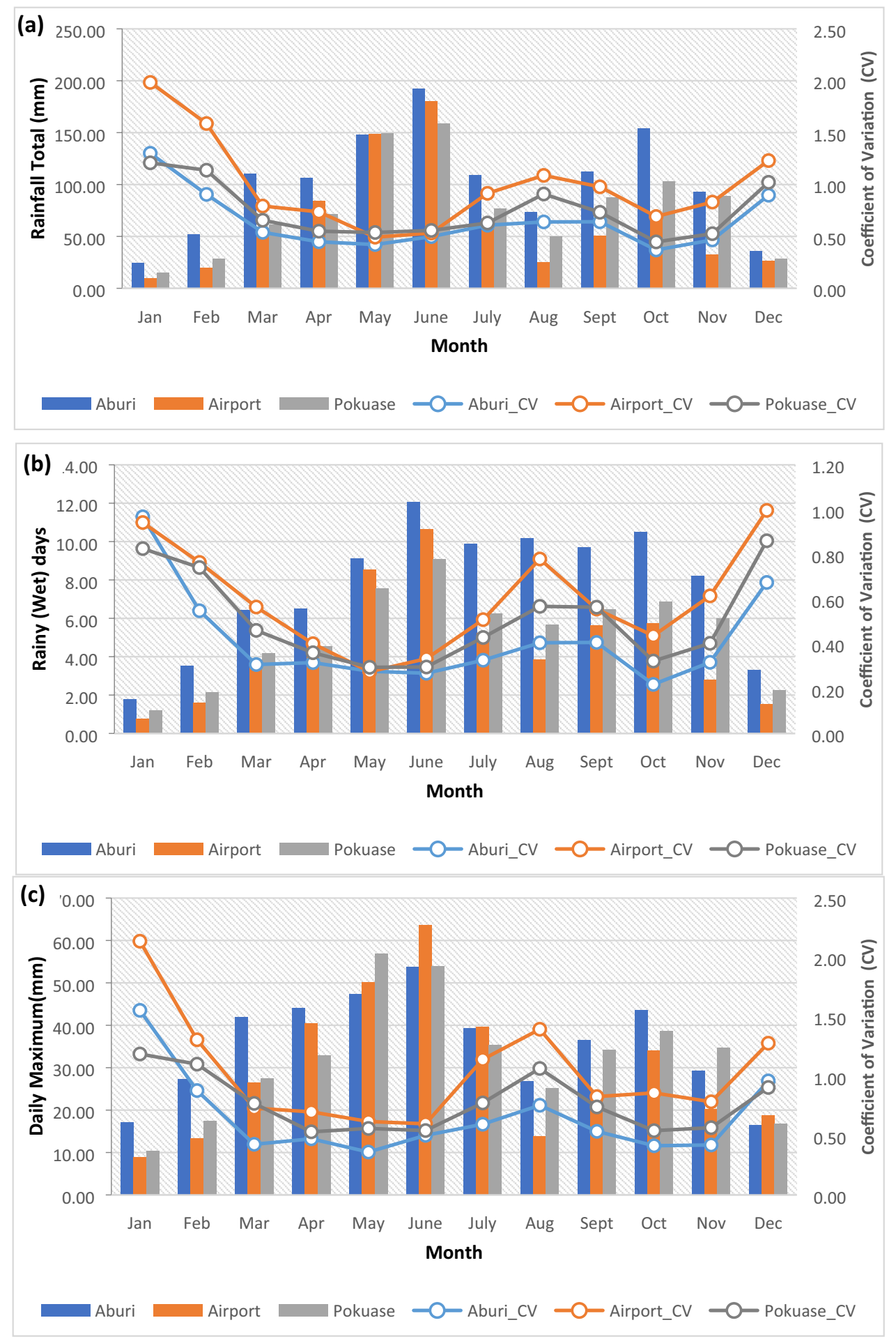

annual time series of the three climatic variables provides a reliable data for further analysis in the Odaw river basin. However, the significant change in the mean annual rainfall value observed at Aburi (Fig. 5a) and mean annual rainy days at Pokuase (Fig. 5b) RD calls for the adjustment of the time series ART and ARD at Aburi and Pokuase stations respectively before it can be used for further analysis.
The monthly time series for the three climatic variables (MRT, MDM and MRD) considered for this study all exhibited very useful and useful homogenous data for the three selected gauge stations as the recorded $p$ values $>0.05$ for all the months with the exception of February (Tables 9 and 10). Aburi station under the MRT and MDM time series exhibited suspected Non-homogenous Time Series 

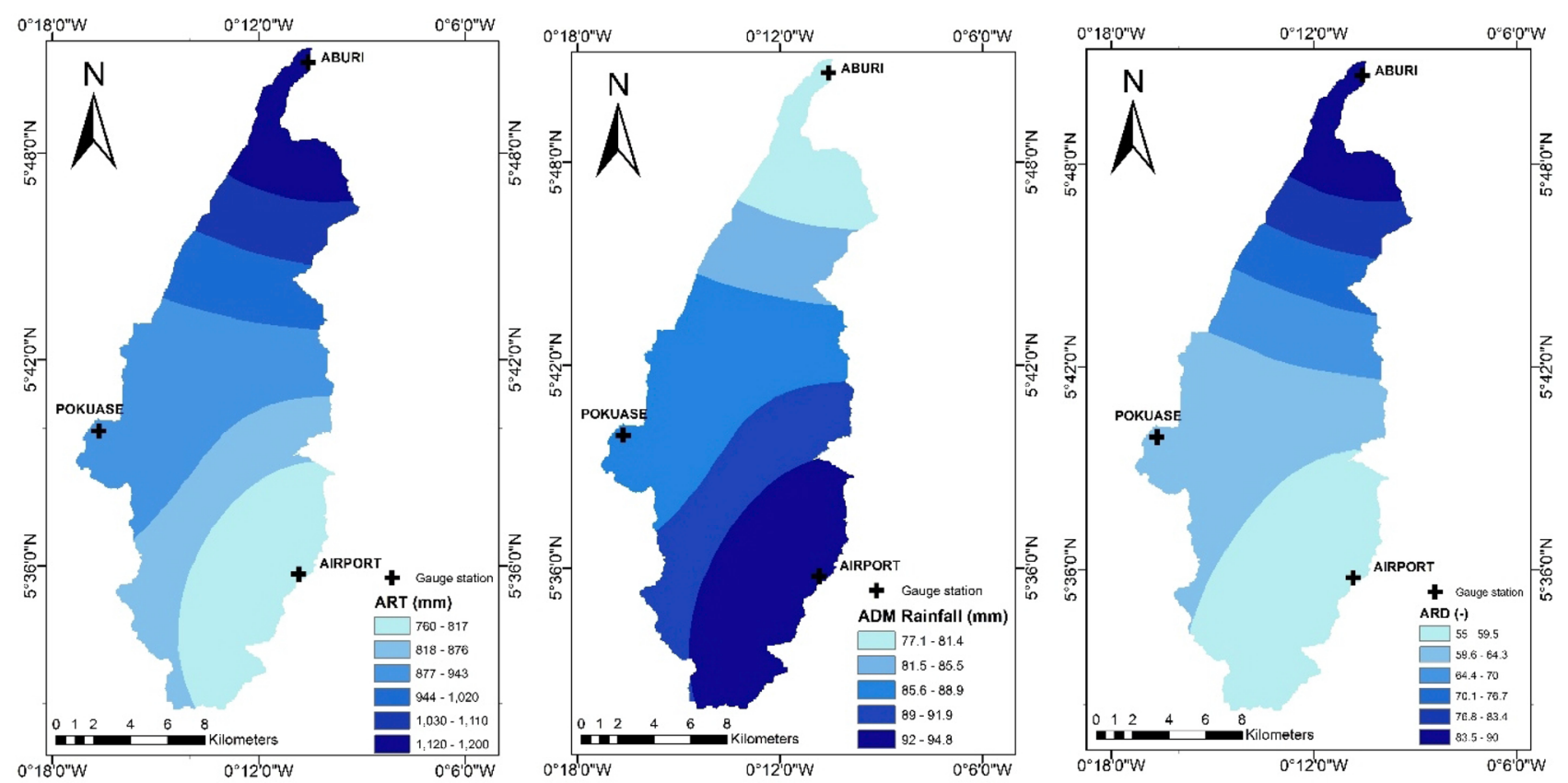

Fig. 4 Spatial distribution of mean annual rainfall (a) ART (b) ADM (c) ARD in ORB from 1980 to 2015

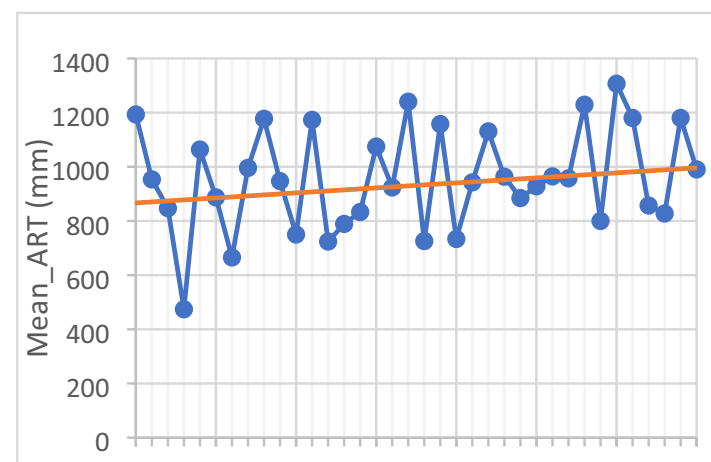

(a) $198019851990 \begin{gathered}1995 \quad 2000 \quad 2005 \quad 2010 \quad 2015 \\ \text { Year }\end{gathered}$

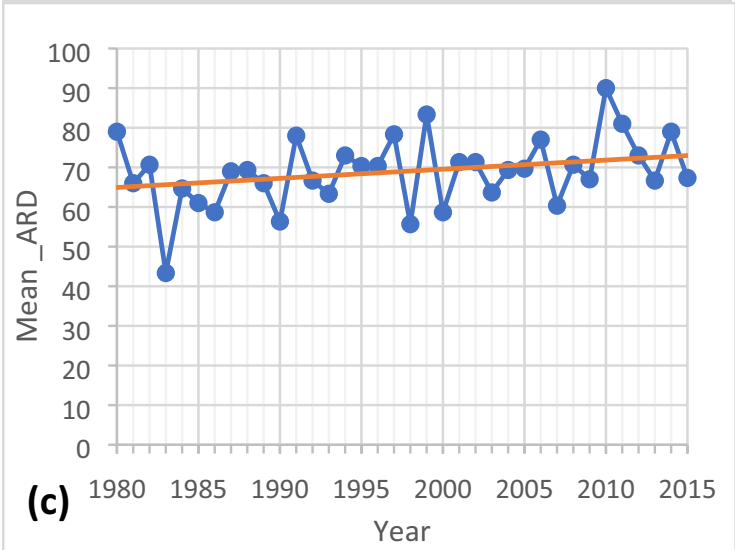

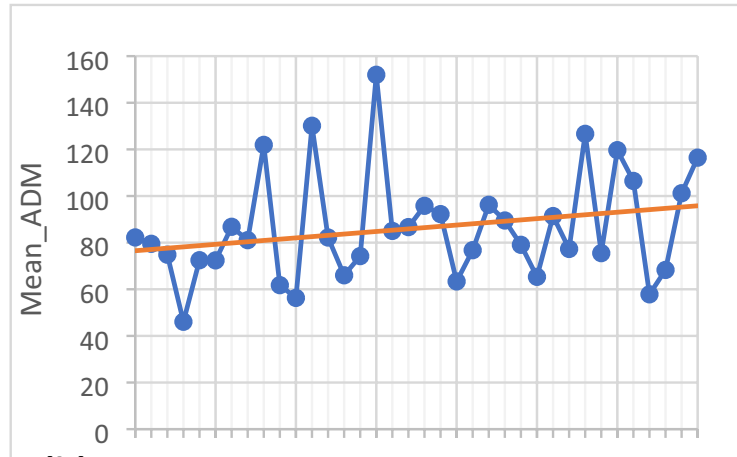

(b) $198019851990 \begin{gathered}1995 \quad 2000 \quad 2005 \quad 2010 \quad 2015 \\ \text { Year }\end{gathered}$

Fig. 5 Mean annual rainfall trend in Odaw basin (a) ART (b) ADM (c) ARD 
given that the $p$ value $<0.05$ for all the three homogeneity test in the month of February. Airport stations on the other hand, exhibited suspected Non-homogenous time series for MDM recording a $p$ value $<0.05$ for all the test in the month of February. This consistency in the month of February recording break point for both MRT and MDM implies a significant change in the mean value of MRT and MDM in the Odaw river basin at Aburi and Airport stations (Fig. 5c-i). This can be interpreted as a possible climate variability in the Odaw basin occurring in the dry seasonal months. This observation seems to agree with the outcome of the exploratory analysis where the dry seasonal months' exhibits increasing trend in rainfall.

The outcome of the homogeneity test implies that the application of the monthly time series for further analysis such hydrological modelling in the Odaw river basin will yield a reliable result for all the months with the exception of February. Adjustment to correct the MRT and MDM time series for February is therefore required if need for further analysis (Table 5).

\subsection{Mann-Kendal trend analysis of annual and monthly rainfall time series}

The Mann-Kendal (MK) test and the Theil and Sen's slope test results at $5 \%$ significance level is shown in Tables 6, 7 and 8 for the annual and monthly rainfall time series during the study period 1980-2015.

\subsubsection{Annual rainfall trend}

MK test recorded a positive trend for ART, ADM and ARD at all the selected stations in the Odaw basin. In the case of ART, positive slope of $3.18 \mathrm{~mm} /$ year, $5.32 \mathrm{~mm} /$ year and $3.7 \mathrm{~mm} /$ year were obtained for Aburi, Airport and Pokuase respectively. Sen's slope test for ADM resulted in $0.37 \mathrm{~mm} /$ year, $0.55 \mathrm{~mm} /$ year and $0.10 \mathrm{~mm} /$ year for Aburi, Airport and Pokuase respectively. Again, Sen's slope test for ARD resulted in 0.06 wet days/year, 0.25 wet days/year and 0.42 wet days/year for Aburi, Airport and Pokuase respectively while Pokuase recorded a significant positive trend.

Figure 5 shows the mean annual rainfall trend for ART, $A D M$ and ARD in the Odaw river basin. An overall nonsignificant positive trend is observed in the Odaw basin for ART and ARD with an average positive slope of $3.7 \mathrm{~mm} /$ year and 0.23 wet days/year. However, significant positive trend with slope value of $0.55 \mathrm{~mm} /$ year was recorded for ADM in the basin. The results are similar to those obtained by Logah et al. [27] on the non-significant increasing trends of mean annual rainfall in Accra. Logah et al. [27], however observed a decline rate of this increasing trend from $8.6 \%$ in $1991-2000$ to $2.6 \%$ in $2001-2010$.

\subsubsection{Monthly rainfall trend}

The MK trend analysis under the monthly rainfall total (MRT) exhibited upward trends in most of the months in the basin with the exception of May, July and September showing a negative trend during the period 1980-2015. A significant positive trend was however observed in the months of April and October while a significant negative trend was recorded in the month of July. The dry seasonal months of December, January and February recorded a significant positive trend at the Airport, Pokuase and Aburi stations respectively (Table 6).

Table 5 Statistics of Rainy (Wet) Days for period (1980-2015) for selected stations in Odaw Basin

\begin{tabular}{|c|c|c|c|c|c|c|c|c|c|c|c|c|c|c|c|}
\hline & \multicolumn{5}{|c|}{ Aburi } & \multicolumn{5}{|c|}{ Airport } & \multicolumn{5}{|c|}{ Pokuase } \\
\hline & $\mathrm{CV}$ & $\begin{array}{l}\text { Min } \\
(\mathrm{mm})\end{array}$ & $\begin{array}{l}\text { Max } \\
(\mathrm{mm})\end{array}$ & Mean (mm) & $\begin{array}{l}\text { Std } \\
\text { Dev }\end{array}$ & $\mathrm{CV}$ & $\begin{array}{l}\text { Min } \\
(\mathrm{mm})\end{array}$ & $\begin{array}{l}\text { Max } \\
(\mathrm{mm})\end{array}$ & Mean (mm) & $\begin{array}{l}\text { Std } \\
\text { Dev }\end{array}$ & $\mathrm{CV}$ & $\operatorname{Min}(\mathrm{mm})$ & $\begin{array}{l}\text { Max } \\
(\mathrm{mm})\end{array}$ & Mean (mm) & Std Dev \\
\hline Annual & 0.13 & 59.00 & 116.00 & 90.42 & 11.24 & 0.17 & 30.00 & 73.00 & 54.53 & 9.35 & 0.18 & 35.00 & 87.00 & 61.64 & 10.97 \\
\hline Jan & 0.97 & 0.00 & 7.00 & 1.81 & 1.77 & 0.94 & 0.00 & 2.00 & 0.78 & 0.72 & 0.83 & 0.00 & 3.00 & 1.22 & 0.99 \\
\hline Feb & 0.55 & 0.00 & 8.00 & 3.44 & 1.93 & 0.76 & 0.00 & 4.00 & 1.64 & 1.22 & 0.74 & 0.00 & 6.00 & 2.11 & 1.62 \\
\hline Mar & 0.31 & 2.00 & 10.00 & 6.44 & 2.03 & 0.56 & 0.00 & 9.00 & 3.86 & 2.24 & 0.46 & 0.00 & 9.00 & 4.17 & 1.98 \\
\hline Apr & 0.32 & 3.00 & 12.00 & 6.53 & 2.12 & 0.40 & 1.00 & 10.00 & 4.86 & 1.96 & 0.36 & 1.00 & 9.00 & 4.56 & 1.68 \\
\hline May & 0.28 & 4.00 & 14.00 & 9.11 & 2.61 & 0.28 & 5.00 & 12.00 & 8.58 & 2.41 & 0.30 & 3.00 & 14.00 & 7.64 & 2.26 \\
\hline June & 0.27 & 5.00 & 19.00 & 11.89 & 3.12 & 0.33 & 4.00 & 20.00 & 10.53 & 3.58 & 0.30 & 4.00 & 14.00 & 9.00 & 2.73 \\
\hline July & 0.33 & 4.00 & 19.00 & 9.83 & 3.31 & 0.51 & 1.00 & 11.00 & 5.17 & 2.70 & 0.43 & 1.00 & 12.00 & 6.11 & 2.58 \\
\hline Aug & 0.41 & 1.00 & 18.00 & 9.97 & 4.07 & 0.78 & 0.00 & 15.00 & 3.67 & 2.89 & 0.57 & 0.00 & 14.00 & 5.53 & 3.18 \\
\hline Sept & 0.41 & 0.00 & 16.00 & 9.50 & 3.86 & 0.56 & 0.00 & 12.00 & 5.47 & 3.04 & 0.56 & 0.00 & 16.00 & 6.39 & 3.72 \\
\hline Oct & 0.22 & 5.00 & 16.00 & 10.36 & 2.23 & 0.44 & 1.00 & 10.00 & 5.64 & 2.51 & 0.32 & 3.00 & 11.00 & 6.83 & 2.27 \\
\hline Nov & 0.32 & 4.00 & 14.00 & 8.14 & 2.64 & 0.61 & 0.00 & 7.00 & 2.75 & 1.75 & 0.40 & 2.00 & 13.00 & 5.97 & 2.48 \\
\hline Dec & 0.67 & 0.00 & 8.00 & 3.42 & 2.23 & 1.00 & 0.00 & 6.00 & 1.58 & 1.56 & 0.86 & 0.00 & 10.00 & 2.33 & 1.97 \\
\hline
\end{tabular}




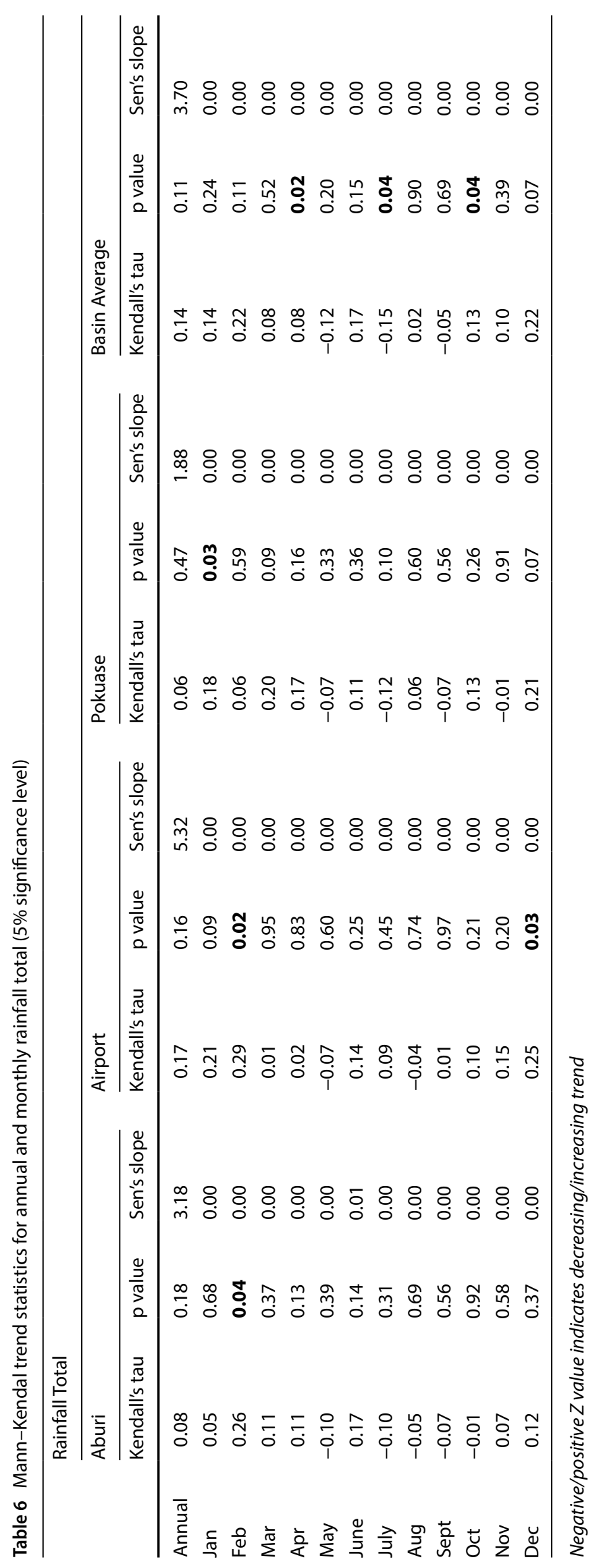



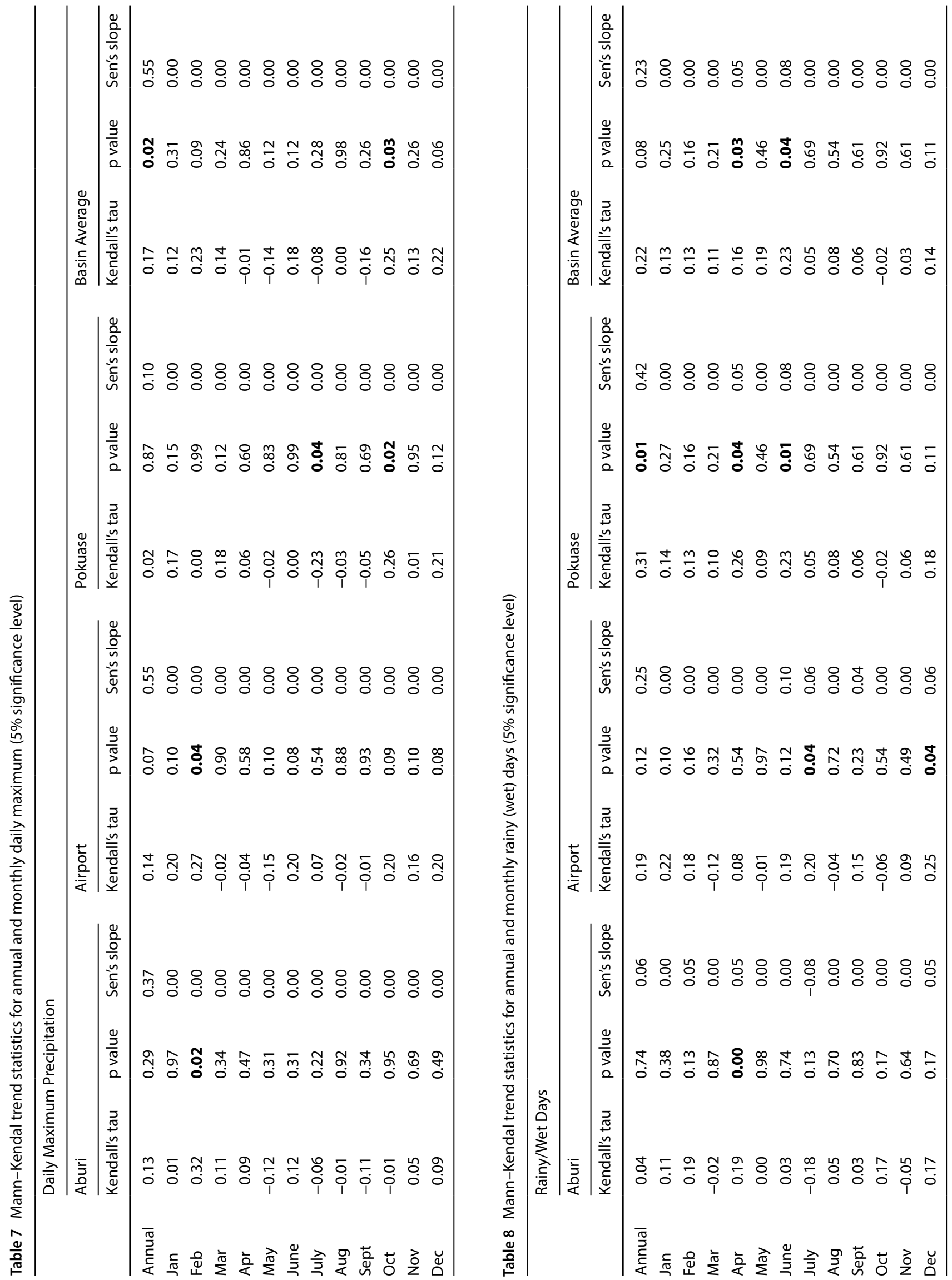


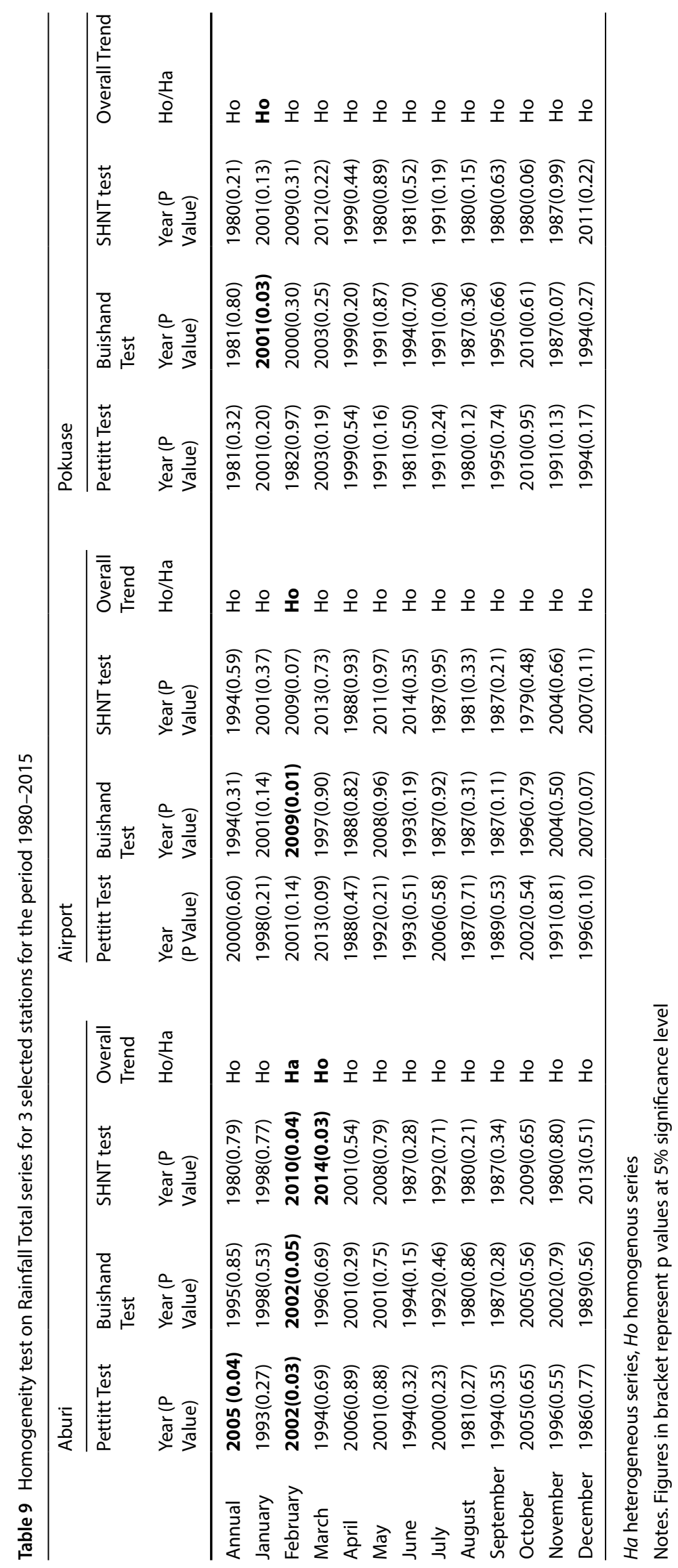




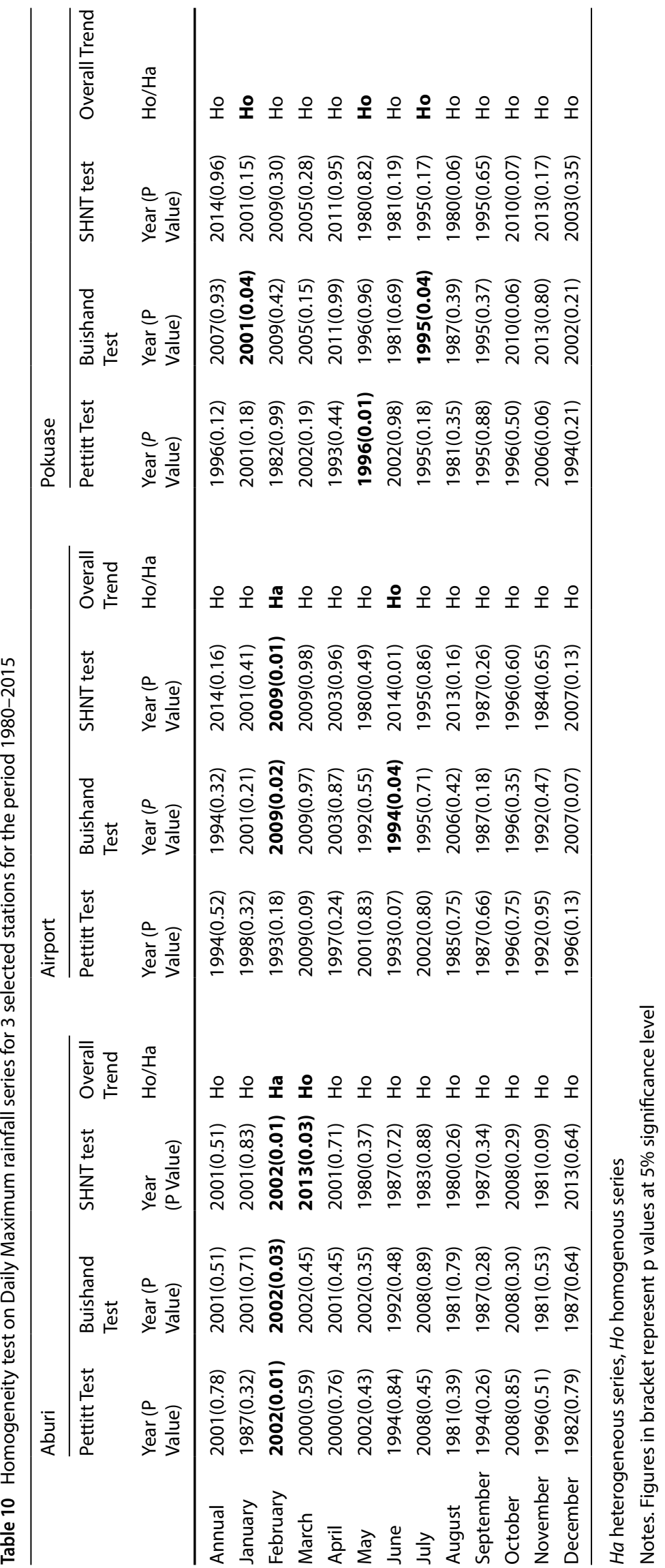


In the case of MDM, the MK trend analysis showed upward trend for most of the months with the exception of April, May, July and September showing a negative trend during the period of study in the basin. A significant positive trend was however observed in the month of October in the basin. The month of February recorded significant upward trends at Aburi and Airport stations while a significant negative trend and positive trend was recorded for the months of July and October respectively at Pokuase station (Table 7).

The MK trend analysis for MRD series (Table 8) exhibited all upward trend for the months with the exception of October in the basin during the study period. However, significant trend was observed in the months of April and June. Significant positive trends were observed in the months of April, July and December occurring at Aburi, Airport and Pokuase stations respectively. Awotwi et al. [9] obtained similar results of a significant increasing trend of rainfall during the dry season in the Lower Pra River Basin of Ghana (Tables 9 and 10).

\subsection{Spatial and temporal variability of rainfall intensity using PCA}

The spatial and temporal variation in rainfall intensity was analyzed using PCA to determine variability in the monthly daily maximum (MDM) rainfall in the ORB. The PCA spatial variation of MDM rainfall from 1980 to 2015 is shown in Fig. 9. The obtained 2 PCs provided a total of $99.9 \%$ variation in ORB higher than the ideal threshold of $70 \%$ obtained by Huang et al. [20]. The PCs were rotated using varimax method to reduce the complex spatial patterns by separating regions with similar temporal variability [49].

From Fig. 9a, the first PC mode (PC-1) explains the maximum variability of $55.9 \%$ in comparison with the location with the reduced rainfall intensity (Fig. 4) occurring at the middle to highland (Northern) part of the basin. This area also shows significant increase in rainy days rainfall with $p$ value for MK test ranging between 0.01 to 0.11 and corresponding slope ranging from 0.368 to $0.419 \mathrm{~mm} /$ year (Figs. 6c, 7c and 8).

From Fig. 9b, the second PC (PC-2) showed that $44.0 \%$ of the variation is most low-lying area at the southeastern part of the ORB. This area corresponds to places with high rainfall intensity (Fig. 4b) ranging from 92 to $95 \mathrm{~mm}$. This area also shows significant decrease in monthly rainfall (Fig. 7).

The temporal dynamics of each PC is shown in Fig. 10. This corresponds to the eigenvalues of each PCs known as PC score $(r)$ and interpreted as the amount of contribution of every month to month rainfall change to the overall variance in rainfall time pattern. $\mathrm{PC}-1$ and $\mathrm{PC}-2$ scored positive correlation coefficients with $\mathrm{r} 1=0.82$ and $\mathrm{r} 2=0.79$ using three-month moving average of the monthly rainfall across ORB.

The findings indicate that PC-1 (Fig. 10a) represent the short-term variation in monthly daily maximum rainfall in the ORB throughout the 36-year period occurring at the
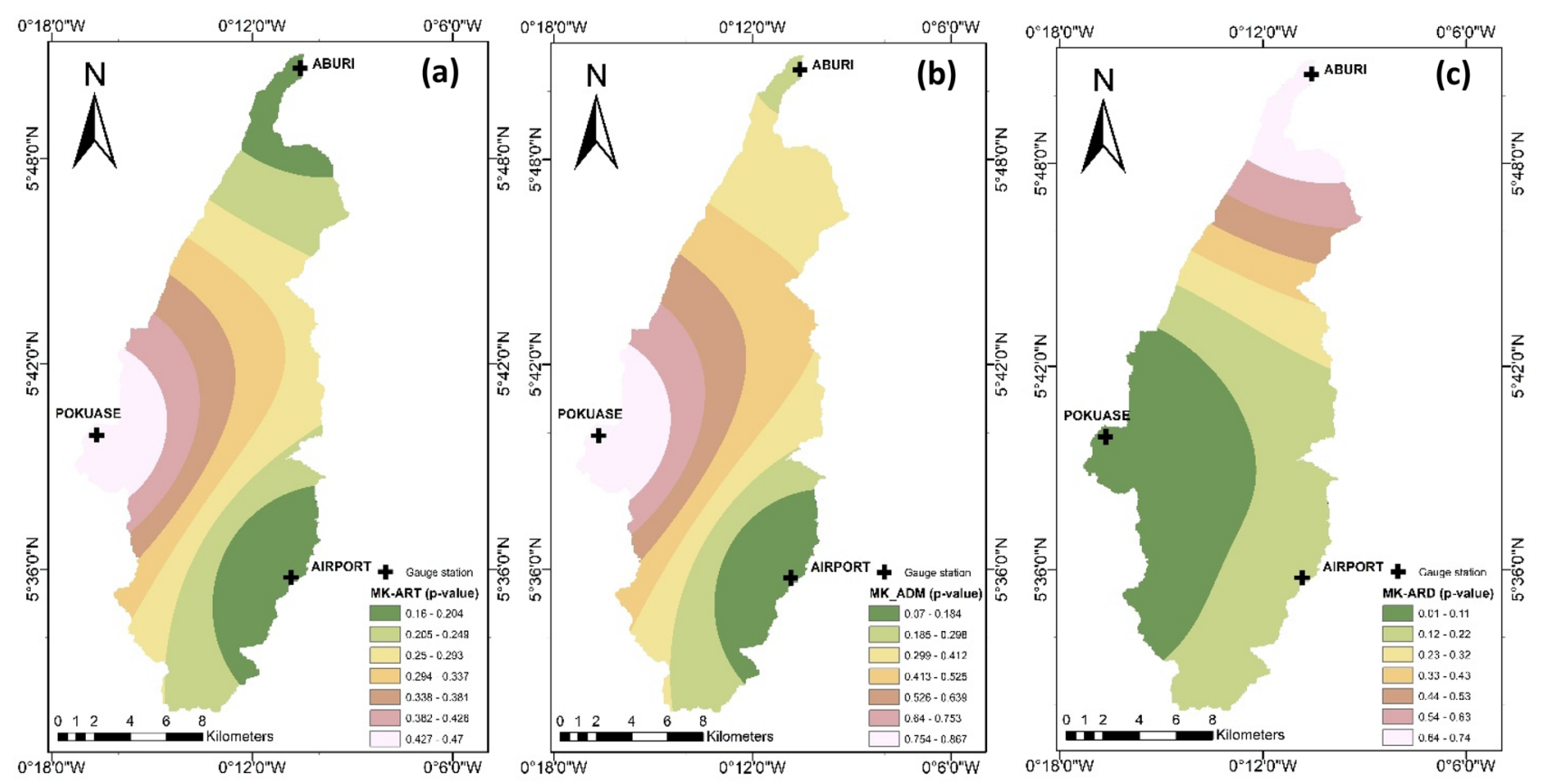

Fig. 6 Spatial variation of Mann-Kendal test (a) ART (b) ADM and (c) ARD at 5\% significance level 

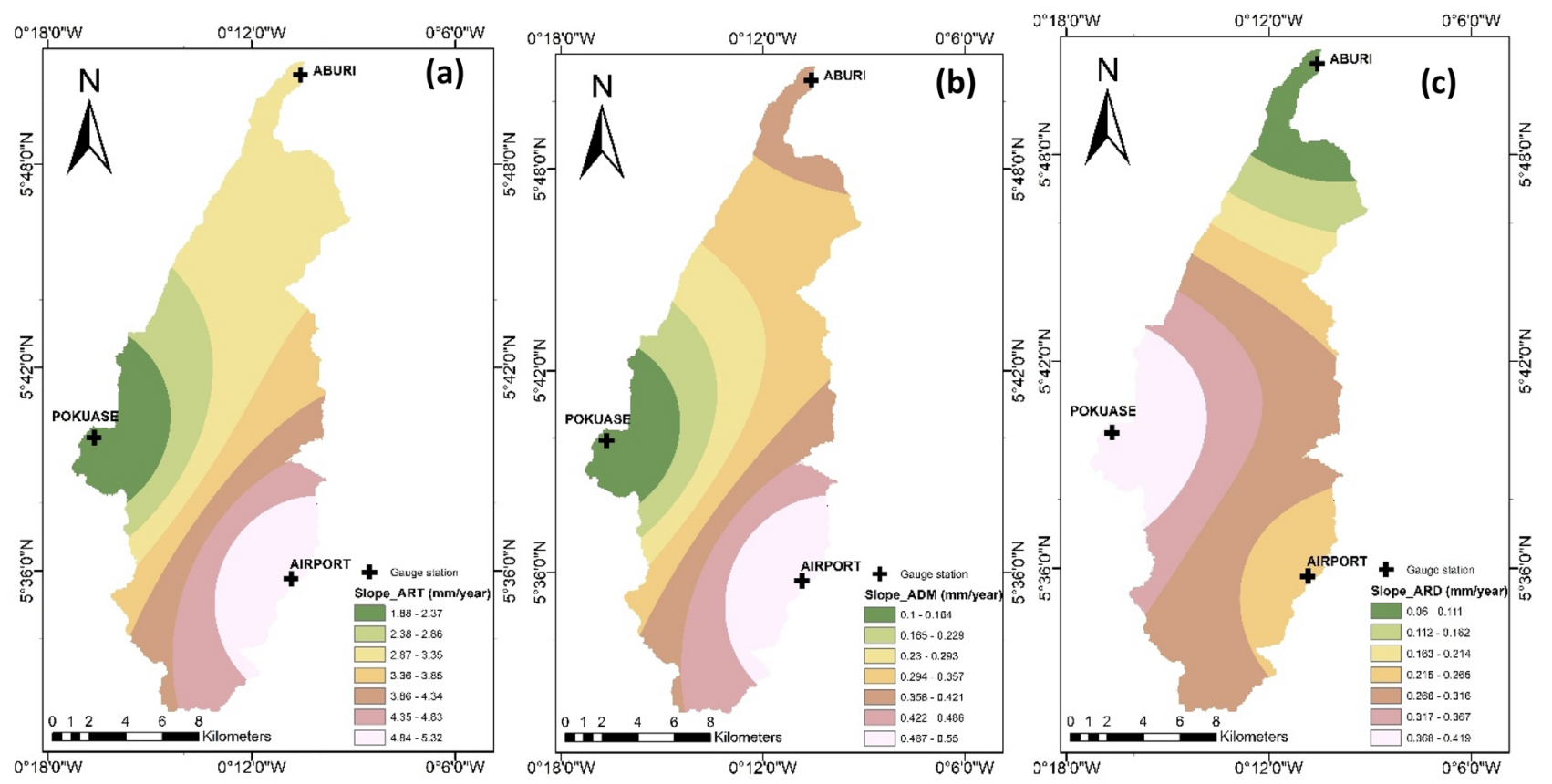

Fig. 7 Spatial variation of Sen's Slope test (a) ART (b) ADM and (c) ARD at 5\% significance level

middle to highland (Northern) part of the basin. The temporal dynamics for PC-2 (Fig. 10b) represent the variation in monthly daily maximum rainfall in the ORB throughout the 36-year period occurring at the lowland (Southern/ coastal) part of the basin.

\subsection{Monthly rainfall variation using wavelet transform}

\subsubsection{The wavelet analysis for rainfall at the Aburi station of Odaw river basin (ORB)}

The results of the wavelet analysis for the Aburi station of ORB are presented in Fig. 11. In Fig. $11 \mathrm{~b}$ wavelet power (actual oscillations of the individual wavelets at each scale and time) for the monthly daily maximum rainfall at the station (Fig. 11a) of ORB is shown.

There is a periodicity between the 0.25 and 0.5 year ( 3 -6 month) scale occurring specifically around the 0.5 year (6th month). Another periodicity (a more pronounced one) also occurred at 1 -year scale, indicating a strong annual signal. This occurred around 1984-1986, 1994-1998, 2004-2008.

These periods are also reported as wet years since it shows a substantial increase in wavelet power (also confirmed in Fig. 11d). No significant information was obtained for low frequency periods (4-32 years scale). The global wavelet power spectrum Fig. 11c shows the integration of the wavelet power with time. This also shows two significant peaks above the $95 \%$ confidence level between the $0.25-0.5$ and the 1 year scale. Figure $11 \mathrm{~d}$ shows the average variance of all scales between the $0.25-1$ year band giving the average year variance with time. Wetter than normal periods can clearly be seen in the years 1995 and 2007.

\subsubsection{The wavelet analysis for rainfall at the airport station of Odaw river basin (ORB)}

The results of the wavelet analysis for the Airport station of ORB are presented in Fig. 12. In Fig. 12b wavelet power (actual oscillations of the individual wavelets at each scale and time) for the monthly daily maximum rainfall at the station (Fig. 12a) of ORB is shown.

There is a periodicity between the 0.25 and 0.5 year ( 3 -6 month) scale occurring specifically around the 0.5 year (6th month). Another periodicity (a more pronounced one) also occurred at 1 year scale, indicating a strong annual signal. This occurred around 1981-1982, 1988, 1991, 1995, 2006-2008. Other periodicity is observed at year 4 and year 8 scale.

These periods are also reported as wet years since it shows a substantial increase in wavelet power (also confirmed in Fig. 12d). No significant information was obtained for low frequency periods (16-32 years scale). The global wavelet power spectrum Fig. $12 \mathrm{c}$ shows the integration of the wavelet power with time. This also shows two significant peaks above the $95 \%$ confidence 
Fig. 8 Change year in annual and monthly rainfall series (a) ART(Aburi), (b) ARD(Pokuase), (c) MRT(Aburi), (d) MRT(Airport), (e) MRT(Pokuase), (f) MDM(Aburi), (g) MDM(Airport), (h) MDM(Pokuase); mu1 and mu2 represent the mean rainfall before and after the change point
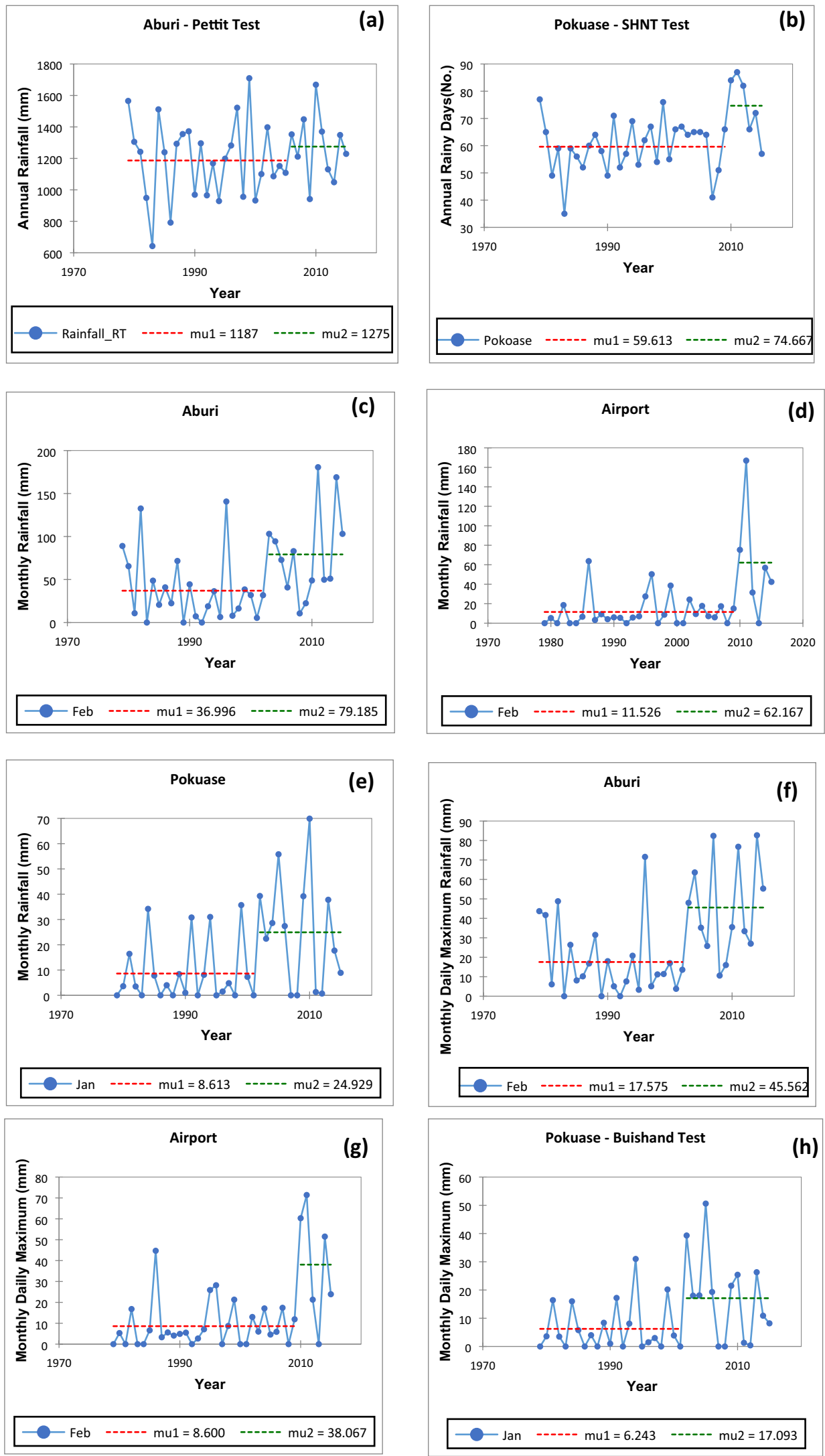

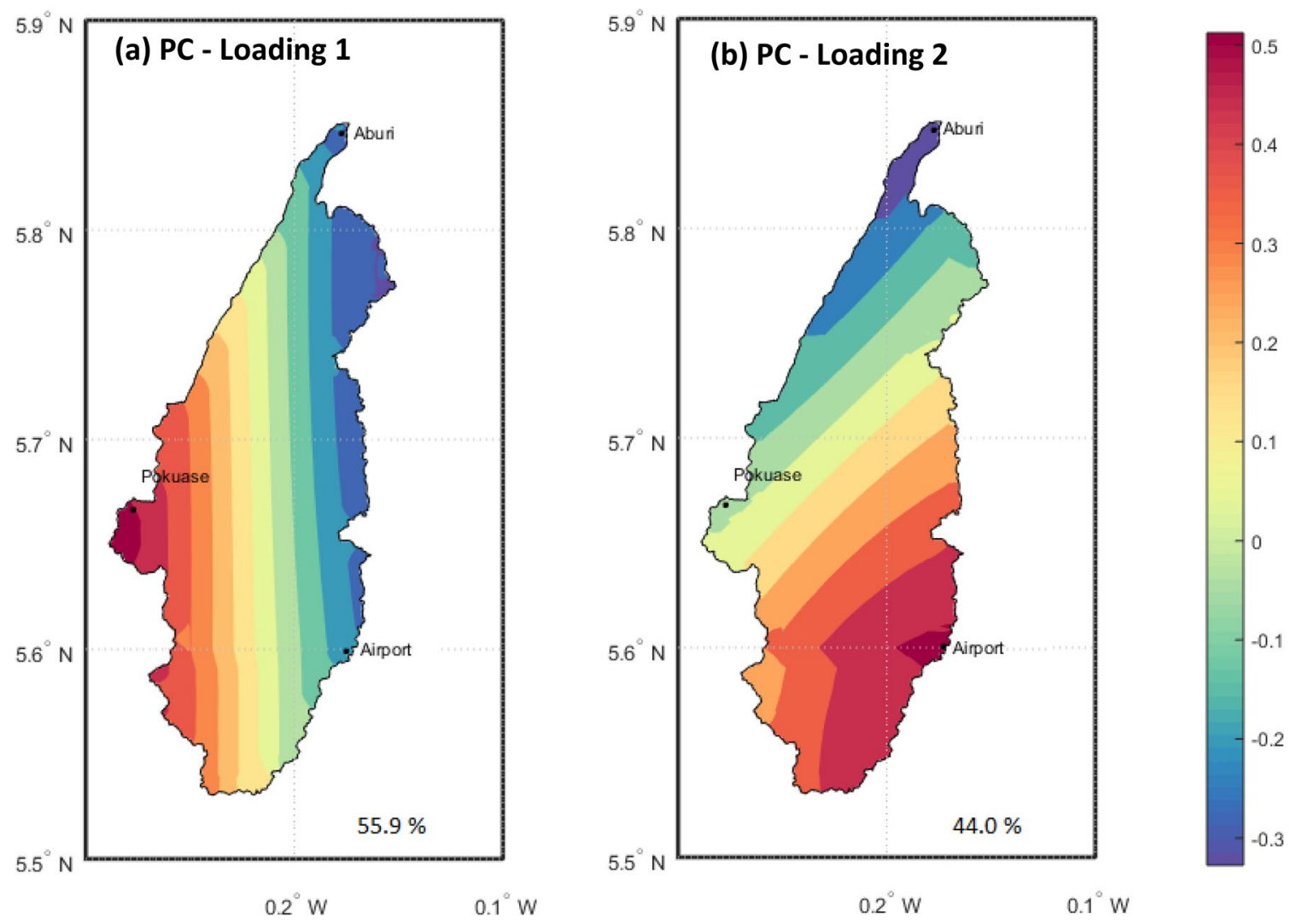

Fig. 9 Spatial distribution of Two PC modes ('loading') of explaining variation in the ORB
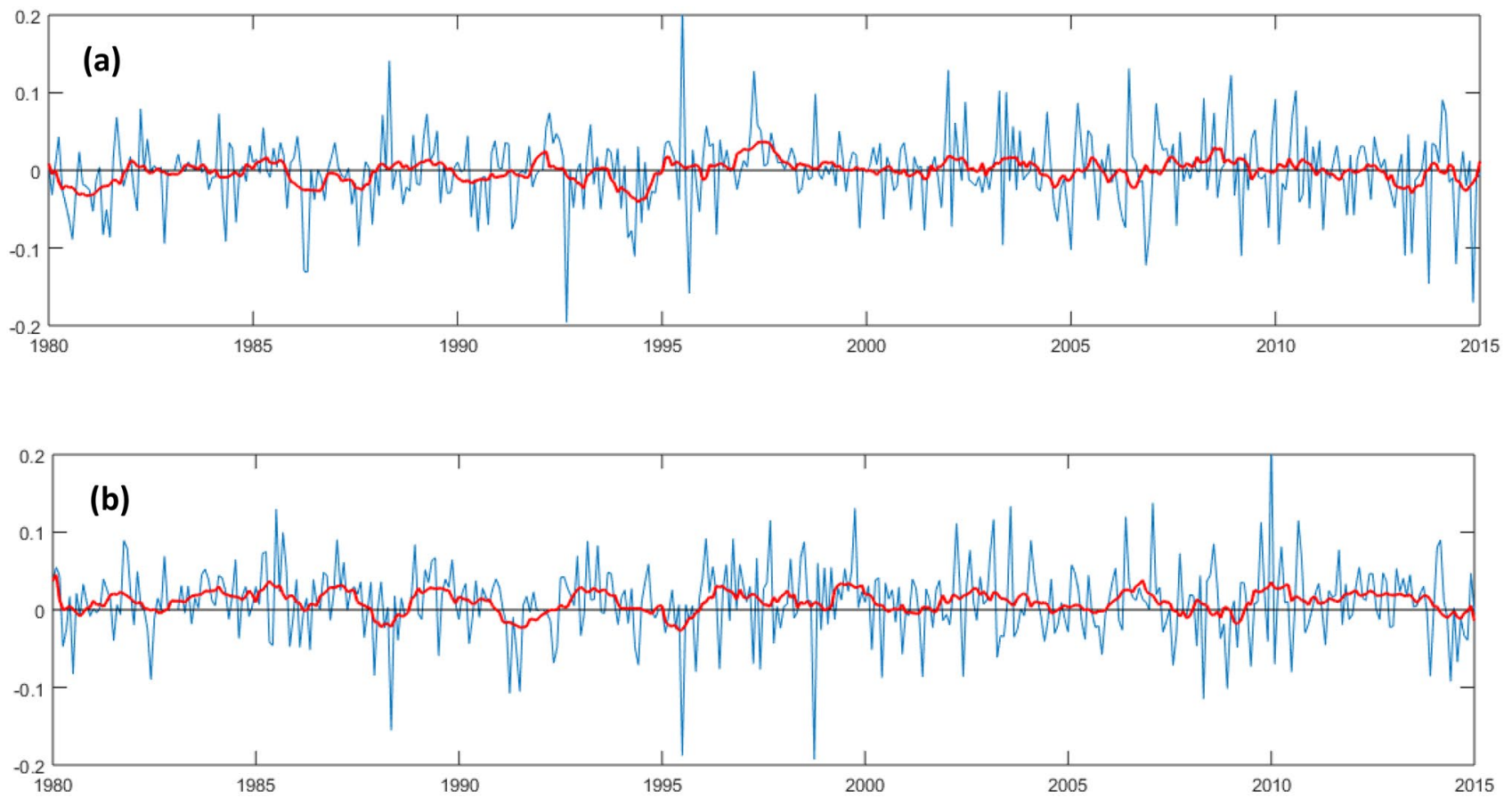

Fig. 10 PC scores modulation of the two (2) principle components. The red line is the 3-month moving average

\section{SN Applied Sciences}


(a) Monthly Rainfall in Aburi from 1980 to 2015

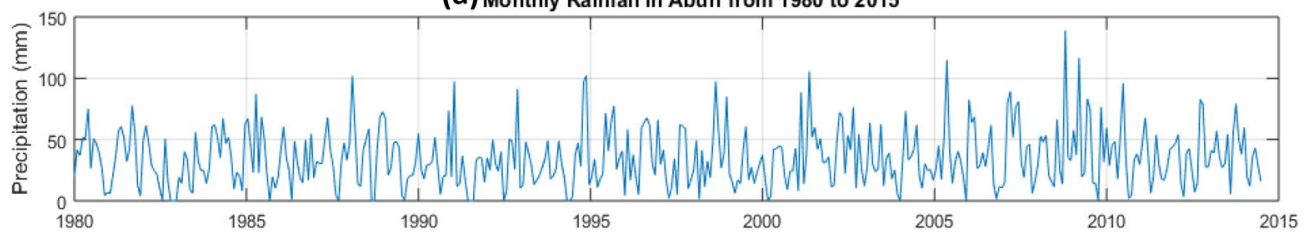

(b) Wavelet Power Spectrum

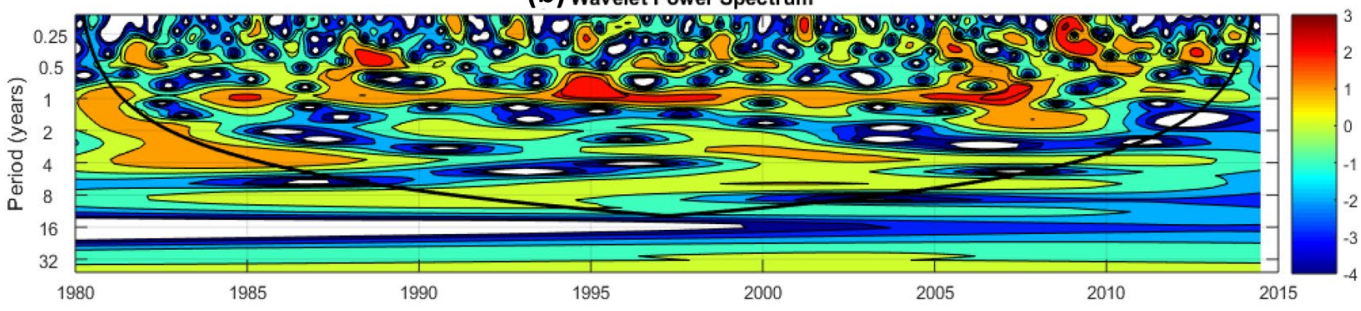

(c) Global WPS

(d) 0.5 - 1 yr Scale-Average Time Series
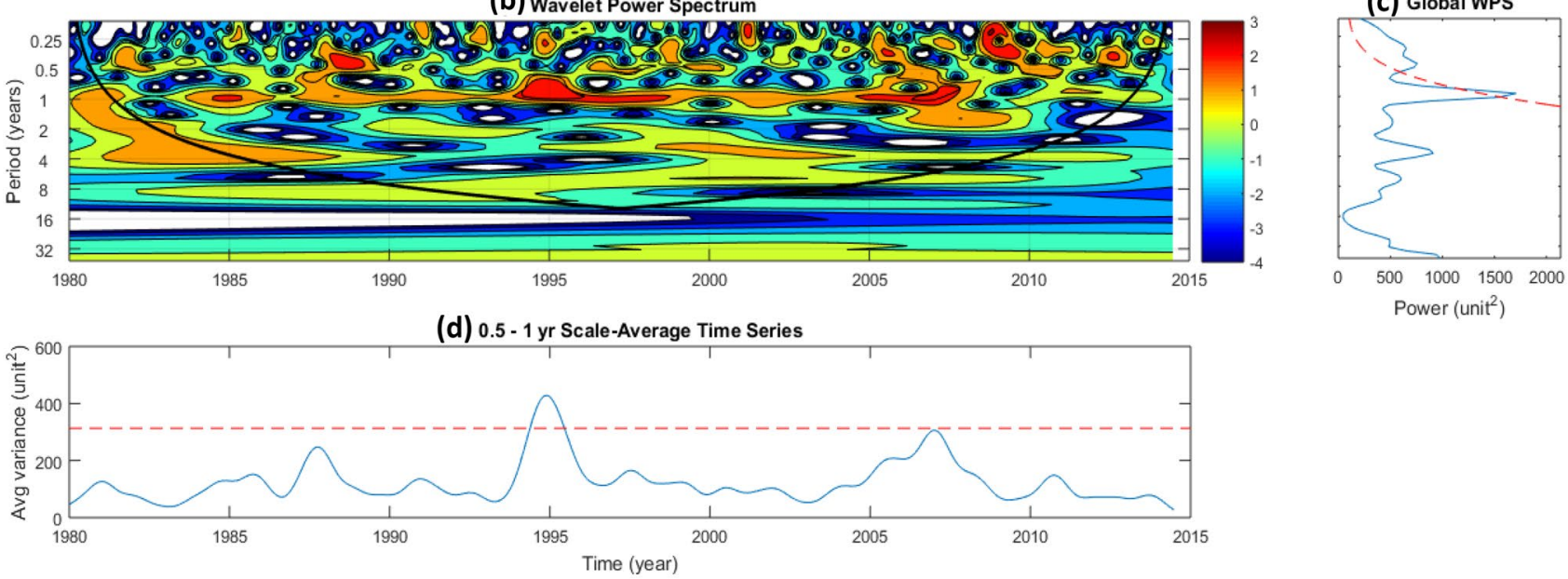

Fig. 11 (a) Monthly daily maximum Rainfall at Aburi for the 19802015 period. (b) Wavelet Power Spectrum at the Station. Crosshatched region is the cone of influence; (c) The global wavelet power spectrum. The dashed line is the $5 \%$ significance level for

the global wavelet spectrum; and (d) Scale-average wavelet power over the $0.5-1$ year band. The dashed line is the $5 \%$ significance level

(a) Monthly Rainfall in Airport from 1980 to 2015

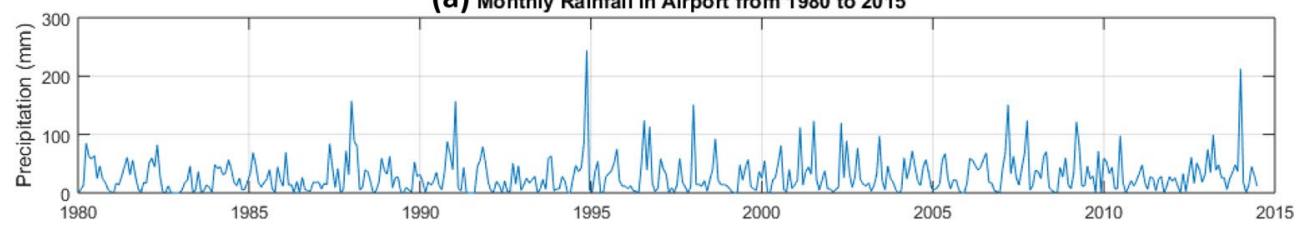

(b) Wavelet Power Spectrum

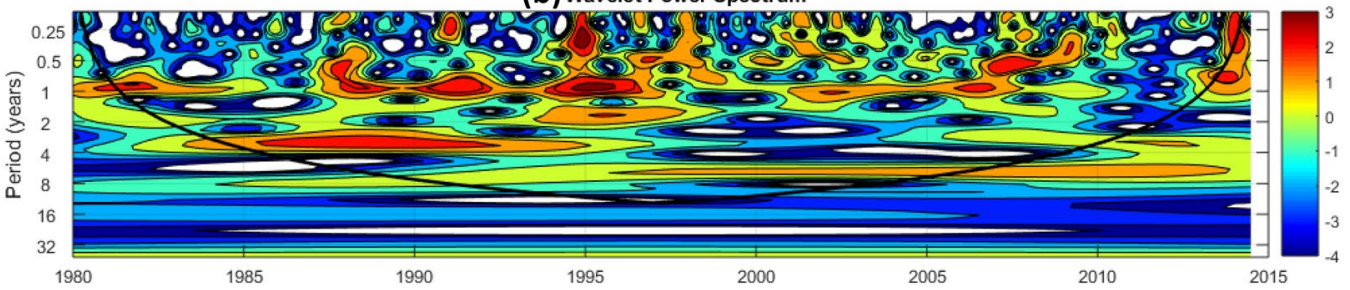

(d) 0.5 - 1 yr Scale-Average Time Series

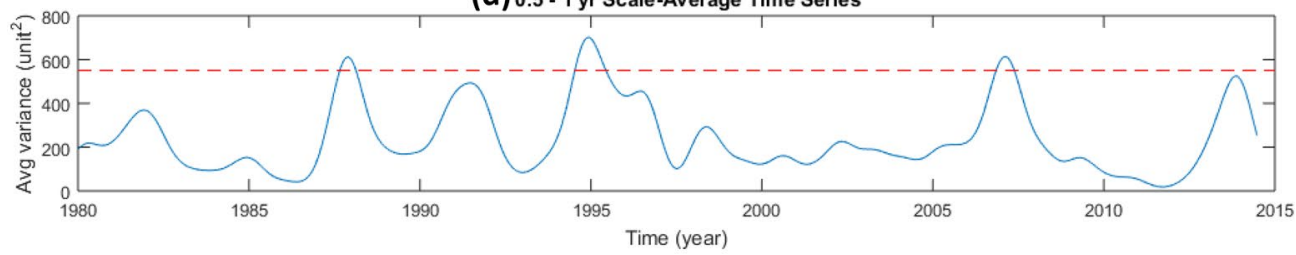

(c) Global WPS

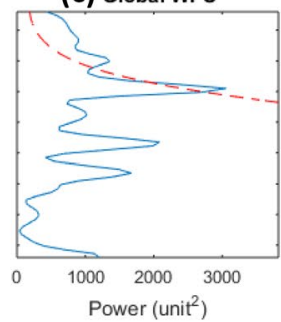

Fig. 12 (a) Monthly daily maximum Rainfall at Airport for the 1980-2015 period. (b) Wavelet Power Spectrum at the Station. Cross-hatched region is the cone of influence; (c) The global wavelet power spectrum. The dashed line is the $5 \%$ significance level for the global wavelet spectrum; and (d) Scale-average wavelet power over the $0.5-1$ year band. The dashed line is the $5 \%$ significance level 
level between the $0.25-0.5$ and the 1 year scale. Figure $12 d$ shows the average variance of all scales between the 0.25 and 1 year band giving the average year variance with time. Wetter than normal periods can clearly be seen in the years 1988, 1991, 19952008 and 2015. These are all periods that floods were recorded in the ORB.

\subsubsection{The wavelet analysis for rainfall at the Pokuase station of Odaw river basin (ORB)}

The results of the wavelet analysis for the Airport station of ORB are presented in Fig. 13. In Fig. 13b wavelet power (actual oscillations of the individual wavelets at each scale and time) for the monthly daily maximum rainfall at the station (Fig. 13a) of ORB is shown.

There is a periodicity between the 0.25 and 0.5 year (3-6 month) scale occurring specifically around the 0.5 year (6th month). Another periodicity (a more pronounced one) also occurred at 1 year scale, indicating a strong annual signal. This occurred around 1981-1982, $1988,1991,1995,2006-2008$. Other periodicity is observed at year 4 and year 8 scale.

These periods are also reported as wet years since it shows a substantial increase in wavelet power (also confirmed in Fig. 13d). No significant information was obtained for low frequency periods (16-32 years scale). The global wavelet power spectrum Fig. $8 c$ shows the integration of the wavelet power with time. This also shows two significant peaks above the $95 \%$ confidence level between the $0.25-0.5$ and the 1 year scale. Figure $13 d$ shows the average variance of all scales between the 0.25 and 1 year band giving the average year variance with time. Wetter than normal periods can clearly be seen in the years 1981, 1991, 2008. These are all periods that floods were recorded in the ORB (Table 11).

\subsection{Comparison of long-term annual to decadal rainfall series trend}

Table 12 shows the Mann-Kendal test and Theils Sen's slope test results of long-term annual series compared with decadal series for ART, ADM and ARD. Considering the decadal series of the 1980-1989 period, a decline trend was recorded at all stations for ART, ADM and ARD rainfall series with corresponding maximum decline slope values; $23.10 \mathrm{~mm} /$ year, $3.929 \mathrm{~mm} /$ year and $2 \mathrm{~mm} /$ year respectively.

The period 1990-1999, however, recorded increasing trend at all stations for ART and ARD. The highest ART was recorded at the Aburi station; $52.167 \mathrm{~mm}$ /year and Pokuase recorded the highest ARD, 1.5 counts/year. Under ADM, upward trends were observed at the Aburi and Airport stations; Theils Sen's values of $1 \mathrm{~mm} /$ year

(a) Monthly Rainfall in Pokuase from 1980 to 2015

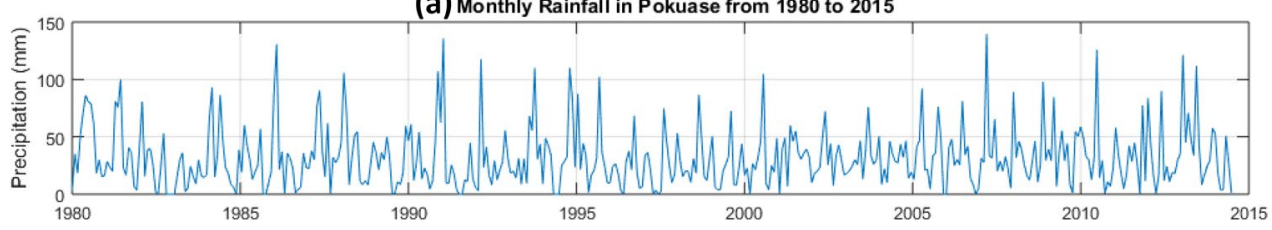

(b) Wavelet Power Spectrum

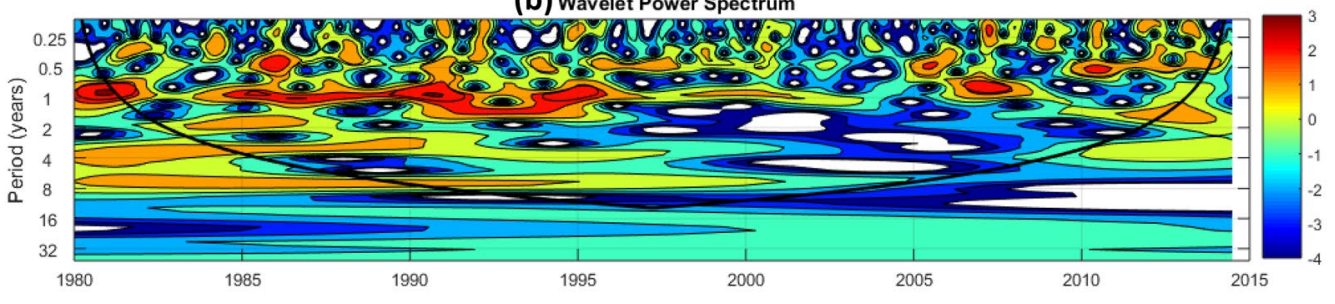

(c) Global WPS

(d) 0.5 - 1 yr Scale-Average Time Series

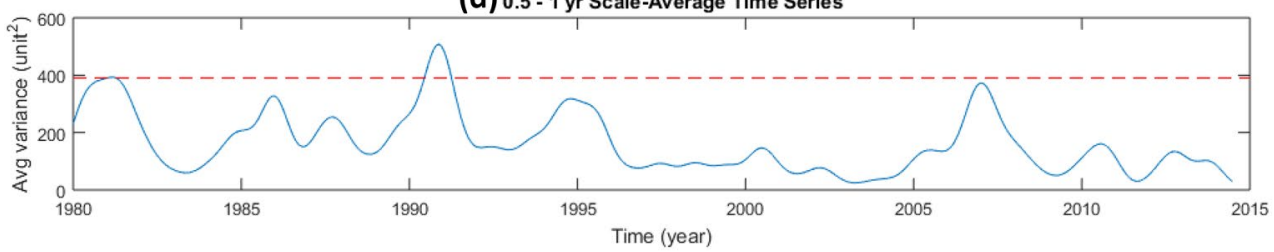

Fig. 13 (a) Monthly daily maximum Rainfall at Pokuase for the 1980-2015 period. (b) Wavelet Power Spectrum at the Station. Cross-hatched region is the cone of influence; (c) The global wavelet power spectrum. The dashed line is the $5 \%$ significance level for the global wavelet spectrum; and (d) Scale-average wavelet power over the $0.5-1$ year band. The dashedline is the $5 \%$ significance level 


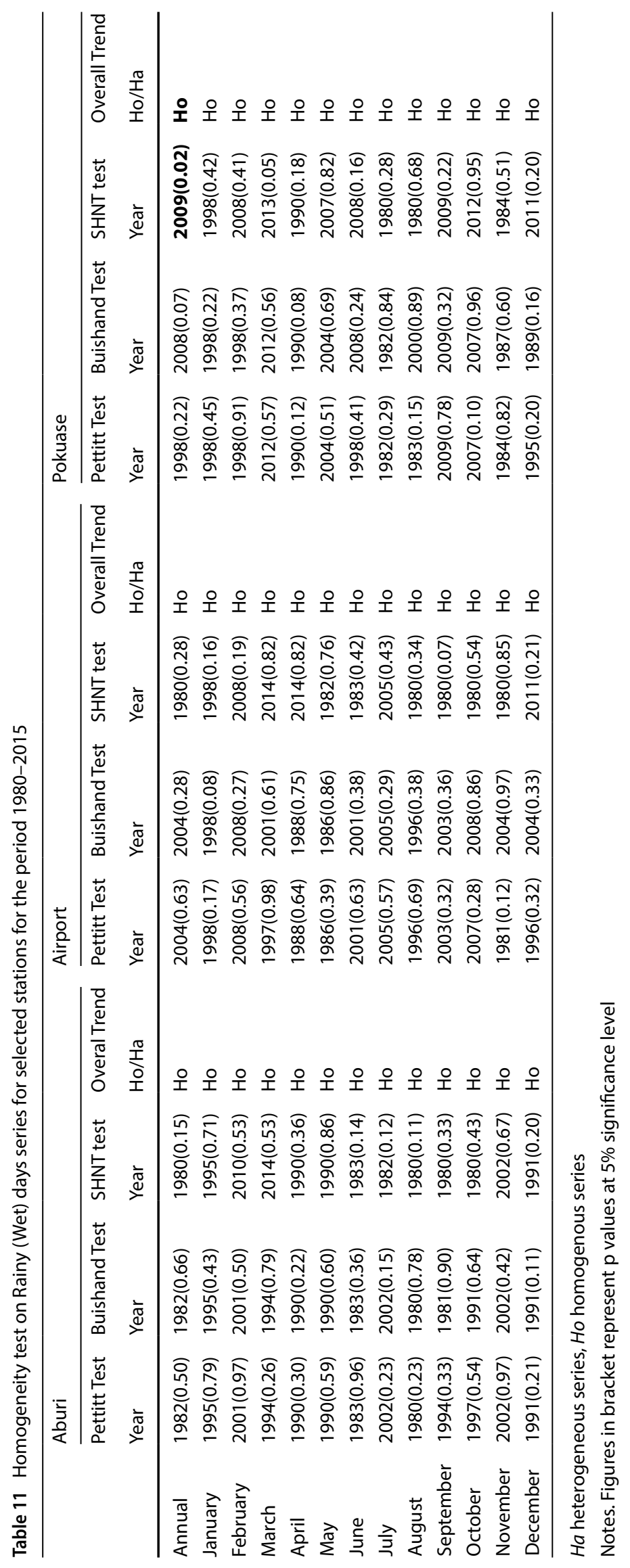


Table 12 Comparism between long term (1980-2015) and decadal durations (1980-1989, 1990-1999, 2000-2009, 2010-2015) at 5\% significance level

\begin{tabular}{|c|c|c|c|c|c|c|c|c|c|c|}
\hline \multirow[t]{2}{*}{ Station } & \multirow[t]{2}{*}{ Year Interval } & \multicolumn{3}{|l|}{ ART } & \multicolumn{3}{|l|}{ ADM } & \multicolumn{3}{|l|}{ ARD } \\
\hline & & Kendall's tau & $\mathrm{p}$ value & Sen's slope & Kendall's tau & $p$ value & Sen's slope & Kendall's tau & $p$-value & Sen's slope \\
\hline \multirow[t]{5}{*}{ Aburi } & 1980-2015 & 0.03 & 0.80 & 1.58 & 0.10 & 0.37 & 0.27 & -0.02 & 0.90 & 0.00 \\
\hline & 1980-1989 & -0.02 & 1.00 & -0.73 & 0.02 & 1.00 & 0.27 & -0.29 & 0.24 & -2.00 \\
\hline & 1990-1999 & 0.29 & 0.28 & 52.17 & 0.07 & 0.86 & 1.00 & 0.14 & 0.65 & 1.38 \\
\hline & 2000-2009 & 0.29 & 0.28 & 19.77 & 0.29 & 0.28 & 2.58 & 0.07 & 0.86 & 0.25 \\
\hline & 2010-2015 & -0.47 & 0.26 & -81.90 & -0.47 & 0.26 & -11.98 & -0.41 & 0.34 & -4.00 \\
\hline \multirow[t]{5}{*}{ Airport } & 1980-2015 & 0.14 & 0.24 & 3.69 & 0.11 & 0.35 & 0.48 & 0.12 & 0.29 & 0.19 \\
\hline & 1980-1989 & -0.27 & 0.28 & -21.37 & -0.06 & 0.88 & -0.20 & -0.46 & 0.06 & -1.80 \\
\hline & 1990-1999 & 0.07 & 0.86 & 5.45 & 0.24 & 0.37 & 5.88 & 0.23 & 0.42 & 1.00 \\
\hline & 2000-2009 & 0.16 & 0.59 & 16.00 & -0.02 & 1.00 & -0.30 & 0.41 & 0.13 & 1.60 \\
\hline & 2010-2015 & 0.07 & 1.00 & 10.17 & 0.20 & 0.71 & 13.10 & -0.33 & 0.45 & -2.40 \\
\hline \multirow[t]{5}{*}{ Pokuase } & 1980-2015 & 0.02 & 0.91 & 0.53 & -0.02 & 0.90 & -0.07 & 0.25 & 0.04 & 0.33 \\
\hline & 1980-1989 & -0.16 & 0.53 & -19.13 & -0.13 & 0.64 & -2.33 & -0.11 & 0.70 & -0.20 \\
\hline & 1990-1999 & 0.11 & 0.72 & 9.93 & -0.23 & 0.42 & -3.85 & 0.33 & 0.21 & 1.50 \\
\hline & $2000-2009$ & -0.02 & 1.00 & -1.62 & 0.29 & 0.28 & 2.85 & -0.18 & 0.53 & -0.33 \\
\hline & 2010-2015 & -0.60 & 0.13 & -99.62 & -0.33 & 0.45 & -2.70 & -0.73 & 0.06 & -5.00 \\
\hline
\end{tabular}

Bold indicate their corresponding p-values less that 0.05

and $5.88 \mathrm{~mm} /$ year respectively, while Pokuase recorded a negative trend with Sen's slope value of $-3.85 \mathrm{~mm} /$ year.

The period 2000-2009 recorded upward trend in ART with slope values of $19.767 \mathrm{~mm} /$ year and $16 \mathrm{~mm} /$ year at Aburi and Airport stations respectively, whiles the Pokuase station experienced a drop in trend, $-1.17 \mathrm{~mm} /$ year. Except at the Airport station, an upward trend in ADM is observed for at all the stations. The pattern of decadal trend for ARD is similar to ART in the 2000-2009 period with upward trends recorded at Aburi and Airport and a negative trend observed at Pokuase. The 2010-2015 period experienced a decline trend in all the climatic variables at all the selected stations, except at the Airport station for ART and ADM which showed an increasing trend with slope values $10.17 \mathrm{~mm} /$ year and $13.10 \mathrm{~mm} /$ year respectively. Logah et al. [27] observed a slight increase in the mean annual rainfall values for Accra over the three decades of 1981-2010 which is also in line with the decadal trend observed in this study during the same period and the same climatic variable.

\section{Conclusions}

This study focused on the Spatio-temporal variability of rainfall trends and homogeneity analysis in the Odaw River Basin on monthly, annual and decadal scales using the climatic variables - total rainfall, wet days and daily maximum rainfall at selected gauge stations over a period spanning 1980-2015, employing observed rainfall data from GMet.

It was observed that the mean value for Annual Rainfall Total (ART), Annual Daily Maximum (ADM) and Annual Rainy Days (ARD) ranging from 760 to $1200 \mathrm{~mm}$, 77.1-94.4 mm and 56-90 day count respectively in the ORB. In general, a non-significant positive trend was recorded in the Odaw basin for ART and ARD with an average positive slope of $3.7 \mathrm{~mm} /$ year and 0.23 wet days/ year while a significant positive trend with slope value of $0.55 \mathrm{~mm} /$ year for ADM in the basin. On the monthly scale, a significant upward trend was observed for the dry seasonal months; December, January and February for the Monthly Rainfall Total (MRT) and Monthly Daily Maximum (MDM) rainfall series during the period at all stations. Homogeneity for both annual and monthly rainfall time series were observed over the stations in the basin by the Pettitt, Alexandersson's SNHT and Buishand's tests.

While the long-term trend analysis shows an increasing trend for ART, ADM and ARD in the basin, the trend on the decadal time series for the same rainfall indices recorded different direction of the trend with high slope values. This signifies underestimation of trends and their corresponding slope magnitude when using long-term time series. Decadal time series therefore provides details of the spatio-temporal rainfall trend while long-term time series averages the variability. PCA results revealed that the spatial variability of rainfall in ORB is very diverse with $55.9 \%$ of the variability located in the middle to highland part while $44.0 \%$ of the variation is occurring mostly in the 
low-lying area at the southeastern part of the ORB. The wavelet analysis also revealed a strong annual periodicity at all the selected stations in the basin.

The results of the study, therefore, provide a better understanding of the spatial and temporal rainfall variability and trends in the Odaw basin. It serves as valuable input information in further research like using hydrological modelling to understand the hydrologic response to the spatial and temporal variability of rainfall in the basin while aiding the formulation of adaptation measures through appropriate strategies for flood risk management of in Accra.

Acknowledgements "This study was funded by the Regional Water and Environmental Sanitation Centre, Kumasi (RWESCK) at the Kwame Nkrumah University of Science and Technology, Kumasi with funding from Government of Ghana and the World Bank under the Africa Centre's of Excellence project'. The views expressed in this paper do not reflect those of the World Bank, Ghana Government and KNUST."

\section{Compliance with ethical standards}

Conflicts of interest The authors declare that they have no conflict of interest.

\section{References}

1. Ackom EK, Adjei KA, Odai SN (2020) Monitoring land-use and land-cover changes due to extensive urbanization in the Odaw River Basin of Accra, Ghana, 1991-2030. Model Earth Syst Environ:1-13. https://doi.org/10.1007/s40808-020-00746-5

2. Ahmad NH, Deni SM (2013) Homogeneity test on daily rainfall series for Malaysia. Malaysian J Ind Appl Math 29:141-150

3. Anim-Gyampo M, Anornu GK, Appiah-Adjei EK, Agodzo SK (2019a) Quality and health risk assessment of shallow groundwater aquifers within the Atankwidi basin of Ghana. Groundwater Sust Dev 9:100217. https://doi.org/10.1016/j.gsd.2019.10021 7

4. Anim-Gyampo M, Anornu GK, Agodzo SK, Appiah-Adjei EK (2019b) Groundwater risk assessment for shallow aquifers within the Atankwidi Basin of (Ghana). In: Advances in sustainable and environmental hydrology, hydrogeology, hydrochemistry and water resources. Springer, Cham, pp 283-286

5. Ansah SO, Ahiataku MA, Yorke CK, Otu-Larbi F, Yahaya B, Lamptey PNL, Tanu M (2020) Meteorological analysis of floods in Ghana. Adv Meteorol 2020. https://doi.org/10.1155/2020/42306 27

6. Amoako C, Frimpong-Boamah E (2014) The three-dimensional causes of flooding in Accra, Ghana. Int J Urban Sustain Dev 7(1):109-129. https://doi.org/10.1080/19463138.2014.984720

7. Attipoe SK (2015) An assessment of flood mitigation measures in Accra, Ghana. Doctoral dissertation. http://ir.knust.edu.gh/ xmlui/bitstream/handle/123456789/7044/ATTIPOE\%2C\%20SEL ASIE\%20KOFI.pdf?sequence=1. Accessed 03 June 2019

8. Awotwi A, Anornu GK, Quaye-Ballard JA, Annor T, Forkuo EK, Harris E, Agyekum J, Terlabie JL (2019) Water balance responses to land-use/land-cover changes in the Pra River Basin of Ghana, 1986-2025. Catena 182:104129. https://doi.org/10.1016/j.caten a.2019.104129
9. Awotwi A, Anornu GK, Quaye-Ballard J, Annor T, Forkuo EK (2017) Analysis of climate and anthropogenic impacts on runoff in the lower Pra River Basin of Ghana. Heliyon 3(12):e00477. https://doi.org/10.1016/j.heliyon.2017.e00477

10. Awotwi A, Kumi M, Jansson PE, Yeboah F, Nti IK (2015) Predicting hydrological response to climate change in the White Volta catchment, W. Africa. J Earth Sci Clim Chang 6(1):1-7

11. Baidu M, Amekudzi LK, Aryee JN, Annor T (2017) Assessment of long-term spatio-temporal rainfall variability over Ghana using wavelet analysis. Climate 5(2):30

12. Burn DH, Elnur MAH (2002) Detection of hydrologic trends and variability. J Hydrol 255(1-4):107-122

13. Contreras J, Ballari D, De Bruin S, Samaniego E (2019) Rainfall monitoring network design using conditioned Latin hypercube sampling and satellite precipitation estimates: an application in the ungauged Ecuadorian Amazon. Int J Climatol 39(4):2209-2226. https://doi.org/10.1002/joc.5946

14. Courty LG (2018) The significance of the spatial variability of rainfall on the numerical simulation of urban floods. Water 10(207):1-17. https://doi.org/10.3390/w10020207

15. Croitoru AE, Holobaca IH, Lazar C, Moldovan F, Imbroane A (2012) Air temperature trend and the impact on winter wheat phenology in Romania. Clim Chang 111(2):393-410. https:// doi.org/10.1007/s10584-011-0133-6

16. Danquah IO (2013) Climate change and its impacts on flooding in Accra-Greater Accra metropolitan assembly. Doctoral dissertation. http://ir.knust.edu.gh/bitstream/12345 6789/5415/1/Msc\%20Thesis_Isaac\%200doi\%20Danquah. pdf. Accessed 23 Apr 2019

17. De Longueville F, Hountondji YC, Kindo I, Gemenne F, Ozer P (2016) Long-term analysis of rainfall and temperature data in Burkina Faso (1950-2013). Int J Climatol 36(13):4393-4405. https://doi.org/10.1002/joc.4640

18. Diomede T, Marsigli C, Nerozzi F, Papetti P, Paccagnella T (2008) Coupling high-resolution precipitation forecasts and discharge predictions to evaluate the impact of spatial uncertainty in numerical weather prediction model outputs. Meteorog Atmos Phys 102(1-2):37-62. https://doi.org/10.1007/ s00703-008-0003-6

19. Ghana Statistical Service (2014) 2010 population and housing census: Accra metropolitan district analytical report, 78

20. Huang J, Xue Y, Sun S, Zhang J (2014) Spatial and temporal variability of drought during 1960-2012 in Inner Mongolia, North China. Quat Int 355:134-144. https://doi.org/10.1016/j. quaint.2014.10.036

21. Jolliffe IT, Cadima J (2016) Principal component analysis: a review and recent developments. Philos Trans R Soc A Math Phys Eng Sci 374(2065):20150202

22. Kabo-Bah AT, Diji C, Nokoe K, Mulugetta Y, Obeng-Ofori D, Akpoti K (2016) Multiyear rainfall and temperature trends in the Volta river basin and their potential impact on hydropower generation in Ghana. Climate 4(4):49

23. Karabörk $M C ̧$, Kahya $E$, Kömüşçü $A U ̈$ (2007) Analysis of Turkish precipitation data: homogeneity and the southern oscillation forcings on frequency distributions. Hydrol Process Int J 21(23):3203-3210. https://doi.org/10.1002/hyp.6524

24. Karpouzos DK, Kavalieratou S, Babajimopoulos C (2010) Trend analysis of precipitation data in Pieria Region (Greece). Eur Water 30:31-40 https://www.ewra.net/ew/pdf/ EW_2010_30_04.pdf. Accessed 16 May 2019

25. Kendall MG (1975) Rank correlation methods, 4th edn. Charles Griffinn, London

26. Lacombe G, McCartney M, Forkuor G (2012) Drying climate in Ghana over the period 1960-2005: evidence from the resampling-based Mann-Kendall test at local and regional 
levels. Hydrologic Sci J 57(8):1594-1609. https://doi. org/10.1080/02626667.2012.728291

27. Logah FY, Obuobie E, Ofori D, Kankam-Yeboah K (2013) Analysis of rainfall variability in Ghana. Int J Latest Res Eng Comput $1(1): 1-8$

28. Longobardi A, Villani P (2010) Trend analysis of annual and seasonal rainfall time series in the Mediterranean area. Int J Climatol 30(10):1538-1546. https://doi.org/10.1002/joc.2001

29. Luo P, He B, Duan W, Takara K, Nover D (2018) Impact assessment of rainfall scenarios and land-use change on hydrologic response using synthetic area IDF curves. J Flood Risk Manage 11:S84-S97. https://doi.org/10.1111/jfr3.12164

30. Mann HB (1945) Nonparametric tests against trend. Econometrica 13:245-259. https://doi.org/10.2307/1907187

31. Michaelides S, Levizzani V, Anagnostou E, Bauer P, Kasparis T, Lane JE (2009) Precipitation: measurement, remote sensing, climatology and modeling. Atmos Res 94(4):512-533

32. Mwale D, Gan TY (2005) Wavelet analysis of variability, teleconnectivity, and predictability of the September-November East African rainfall. J Appl Meteorol 44(2):256-269

33. Nyarko BK (2000) Flood risk zoning of Ghana: Accra experience. Int Arch Photogramm Remote Sens 33(B7/3, PART 7):1039-1050

34. Nyatuame M, Owusu-Gyimah V, Ampiaw F (2014) Statistical analysis of rainfall trend for Volta region in Ghana. Int J Atmos Sci:1-11. https://doi.org/10.1155/2014/203245

35. Ofori-Sarpong E, Annor J (2001) Rainfall over Accra, 1901-90. Weather 56(2):55-62. https://doi.org/10.1002/j.1477-8696.2001. tb06535.x

36. Omotosho JB, Abiodun BJ (2007) A numerical study of moisture buildup and rainfall over West Africa. Meteorol Appl 14:209-225. https://doi.org/10.1002/met.11

37. Onyutha C, Tabari H, Taye MT, Nyandwaro GN, Willems P (2016) Analyses of rainfall trends in the Nile River Basin. J Hydro Environ Res 13:36-51. https://doi.org/10.1016/j.jher.2015.09.002

38. Othman M, Ash'aari ZH, Mohamad ND (2015) Long-term daily rainfall pattern recognition: application of principal component analysis. Procedia Environ Sci 30:127-132

39. Quaye-Ballard JA, Okrah TM, Andam-Akorful SA, Awotwi A, Antwi T, Osei-Wusu W, Quaye-Ballard NL (2020) Spatiotemporal dynamics of rainfall in upper east region of Ghana, West Africa, 1981-2016. SN Appl Sci 2(10):1-12. https://doi.org/10.1007/ s42452-020-03463-X

40. Shao J, Wang J, Lv S, Bing J (2016) Spatial and temporal variability of seasonal precipitation in Poyang Lake basin and possible links with climate indices. Hydrol Res 47(S1):51-68

41. Shawul AA, Chakma S (2020) Trend of extreme precipitation indices and analysis of long-term climate variability in the upper Awash basin, Ethiopia. Theor Appl Climatol 140:635-652. https ://doi.org/10.1007/s00704-020-03112-8

42. Shen L, Lu L, Hu T, Lin R, Wang J, Xu C (2018) Homogeneity test and correction of daily temperature and precipitation data (1978-2015) in North China. Adv Meterol. https://doi. org/10.1155/2018/4712538

43. Suhaila J, Deni SM, Jemain AA (2008) Detecting inhomogeneity of rainfall series in peninsular Malaysia. Asia-Pacific J Atmos Sci 44(4):369-380. https://doi.org/10.1007/s00703-017-0537-6

44. Tapiador FJ, Turk FJ, Petersen W, Hou AY, García-Ortega E, Machado LA et al (2012) Global precipitation measurement: methods, datasets and applications. Atmos Res 104:70-97

45. Wang M, Zhang DQ, Su J, Dong JW, Tan SK (2018) Assessing hydrological effects and performance of low impact development practices based on future scenarios modeling. J Clean Prod 179:12-23. https://doi.org/10.1016/j.jclepro.2018.01.096

46. Wang $Y, X u Y$, Lei $C$ et al (2016) Spatio-temporal characteristics of precipitation and dryness/wetness in Yangtze River Delta, eastern China, during 1960-2012. Atmos Res 172-173:196-205

47. Wijngaard JB, Klein Tank AM, Können GP (2003) Homogeneity of 20th century European daily temperature and precipitation series. Int J Climatol J R Meteorol Soc 23(6):679-692. https://doi. org/10.1002/joc.906

48. Yue S, Hashino M (2003) Long term trends of annual and monthly precipitation in Japan 1. J Am Water Res Assoc 39(3):587-596

49. Zhao G, Mu X, Hörmann G, Fohrer N, Xiong M, Su B, Li X (2012) Spatial patterns and temporal variability of dryness/wetness in the Yangtze River Basin, China. Quat Int 282:5-13. https://doi. org/10.1016/j.quaint.2011.10.020 